\title{
OPEN Electro-steric opening of the CLC-2 chloride channel gate
}

\author{
José J. De Jesús-Pérez ${ }^{1}$, G. Arlette Méndez-Maldonado ${ }^{2}$, Ana E. López-Romero ${ }^{1}$, \\ David Esparza-Jasso', Irma L. González-Hernández ${ }^{2}$, Víctor De la Rosa ${ }^{3}$, \\ Roberto Gastélum-Garibaldi², Jorge E. Sánchez-Rodríguez ${ }^{2}$ \& Jorge Arreola ${ }^{1 \bowtie}$
}

The widely expressed two-pore homodimeric inward rectifier CLC-2 chloride channel regulates transepithelial chloride transport, extracellular chloride homeostasis, and neuronal excitability. Each pore is independently gated at hyperpolarized voltages by a conserved pore glutamate. Presumably, exiting chloride ions push glutamate outwardly while external protonation stabilizes it. To understand the mechanism of mouse CLC-2 opening we used homology modelling-guided structure-function analysis. Structural modelling suggests that glutamate E213 interacts with tyrosine Y561 to close a pore. Accordingly, Y561A and E213D mutants are activated at less hyperpolarized voltages, re-opened at depolarized voltages, and fast and common gating components are reduced. The double mutant cycle analysis showed that E213 and Y561 are energetically coupled to alter CLC-2 gating. In agreement, the anomalous mole fraction behaviour of the voltage dependence, measured by the voltage to induce half-open probability, was strongly altered in these mutants. Finally, cytosolic acidification or high extracellular chloride concentration, conditions that have little or no effect on WT CLC-2, induced reopening of 561 mutants at positive voltages presumably by the inward opening of E213. We concluded that the CLC-2 gate is formed by Y561-E213 and that outward permeant anions open the gate by electrostatic and steric interactions.

Gating is a fundamental property whereby ion channels open a permeation pathway so that ions can passively flow through membranes, ensuring electric communication ${ }^{1-4}$. In some channels, a sudden change in the membrane potential, ligand binding or lipid bilayer deformation, triggers a propagating cascade of structural rearrangements that opens the permeation pathway ${ }^{1-7}$. Alternatively, gating could rely on the permeant ion as reported for $\mathrm{K}^{+}$and $\mathrm{Cl}^{-}$channels. This hypothesis suggests that ion permeation is coupled to channel gating, a mechanism that has been proposed to operate in channels and transporters ${ }^{9}$.

The $\mathrm{Cl}^{-}$channels (CLC-0, CLC-1, CLC-2, CLC-Ka, and CLC-Kb) and $\mathrm{Cl}^{-} / \mathrm{H}^{+}$exchangers of the CLC protein family are structurally conserved ${ }^{10}$. All are dimers harbouring a pore in each monomer that is controlled by a highly conserved glutamate residue known as glutamate gate located inside the pore ${ }^{11-14}$. Since CLC channels are gated by voltage despite lacking a canonical voltage sensor ${ }^{10}$, the pore structure suggests that gating may occur unconventionally ${ }^{8}$. The glutamate gate could be opened by repulsion or by protonation when voltage drives a permeant anion or a proton into the pore ${ }^{12,15-22}$. Gating by permeant anions has been proposed for CLC-0 and CLC-1 channels ${ }^{18,19,23,24}$. However, the proton sensitivity analysis of a conservative mutation at the glutamate gate, suggested that protonation of this residue by intracellular protons is the major voltage-dependent step in CLC-0 gating ${ }^{21,25}$, a process catalysed by extracellular $\mathrm{Cl}^{-}$anions ${ }^{26}$. CLC-2 gating deviates from the latter scenario; it relies on hyperpolarization and intracellular $\mathrm{Cl}^{-}$while depolarization causes deactivation ${ }^{15,27,28}$. Moreover, voltage-dependent gating can occur even with impermeable anions present in the cytosolic side ${ }^{17}$. Remarkably, intracellular acidification has little or no effect on gating whereas extracellular acidification increases the open probability ${ }^{29}$. Still, extracellular protonation cannot explain CLC-2 activation because gating happens under unfavourable protonation conditions ${ }^{16,17}$. Given these observations, we proposed that hyperpolarization drives $\mathrm{Cl}^{-}$inside the pore causing E213 to open by electrostatic and steric repulsion ${ }^{15,17}$, then extracellular protonation of E213 residue stabilizes the open conformation ${ }^{16}$. However, the molecular details supporting this mechanism are still waiting to be described and evidence supporting the hypothesis is still scarce.

${ }^{1}$ Physics Institute, Universidad Autónoma de San Luis Potosí, Ave. Dr. Manuel Nava \#6, 78290 San Luis Potosí, SLP, Mexico. ${ }^{2}$ Departamento de Física, Centro Universitario de Ciencias Exactas e Ingenierías, Universidad de Guadalajara, Blvd. M. García Barragán \#1421, 44430 Guadalajara, Jalisco, Mexico. ${ }^{3}$ CONACYT, School of Medicine, Universidad Autónoma de San Luis Potosí, Ave. V. Carranza 2005, Los Filtros, 78290 San Luis Potosí, SLP, Mexico. ${ }^{\varpi}$ email: arreola@dec1.ifisica.uaslp.mx 
In this work, we performed a functional analysis combined with site-directed mutagenesis of critical residues for gating located within the pore to determine the molecular entities involved in the opening of the pore gate in CLC-2, a Cl- channel highly expressed throughout the central nervous system that controls chloride transport, extracellular chloride homeostasis, neuronal excitability, aldosterone secretion and heart rate ${ }^{10,28,30}$.

\section{Results}

The homology structure of CLC-2. The structure of the CLC-2 chloride channel remains unsolved. In this work, we utilized homology modelling to obtain model structures of the mouse CLC-2. We constructed CLC-2 ${ }^{\mathrm{CLC}-\mathrm{K}}$ based on bovine CLC-K structure (PDB: 5 TQQ $^{14}$ ), and CLC-2 ${ }^{\mathrm{CLC}-1}$ based on human CLC-1 structures (PDBs: 6COY, 6QVB, 6QV6, 6QVU ${ }^{13,31}$ ) available later. mCLC-2 is $48.77 \%$ identical to CLC-K within the transmembrane domain (TMD; Fig. 1A). The pore regions are $63.89 \%$ identical, but a valine replaces the glutamate gate in CLC-K. Compared to hCLC-1, CLC-2 is $67.98 \%$ identical within TMD and $83.33 \%$ within the pore region (Fig. 1A, blue region). CLC-2 ${ }^{\mathrm{CLC}-\mathrm{K}}$ and CLC-2 ${ }^{\mathrm{CLC}-1}$ homodimers are rhombus-shaped with a TMD comprising $17 \alpha$-helices (termed B-R) (Fig. 1B). Helix A (residues 1 to 96), which is not in the template structures, could not be modelled. Only CLC-2 ${ }^{\text {CLC-K }}$ included the C-terminus with two cystathionine- $\beta$-synthase (CBS) domains (Fig. 1C). Interestingly, this homology structure showed the presence of an alternative water-filled cavity towards the intracellular side (indicated by the yellow asterisk in the grey square in Fig. 1C). However, it seems to be isolated from the canonical pore (indicated by dark blue in the inset in Fig. 1C).

From these models, we inferred that the canonical CLC-2 pore (orange box in Fig. 1C) is formed by residues 164APQAVGSGIPEM175, 211GKEG214, 458TTIPVPCGAFMP469, and 561YDSIIRIK568 located at the $\mathrm{N}$-termini of $\alpha \mathrm{D}, \alpha \mathrm{F}, \alpha \mathrm{N}$, and $\alpha \mathrm{R}$ helices, respectively. E213 adopts different rotational angles depending on the template (Fig. 1D). While E213 in the CLC-2 $2^{\mathrm{CLC}-\mathrm{K}}$ (green) or 6QV6-based CLC-2 ${ }^{\mathrm{CLC}-1}$ (cyan) is directed to the extracellular side, in the 6COY-based CLC-2 ${ }^{\mathrm{CLC}-1}$ (salmon) E213 pointed to $\mathrm{F}$ helix allowing occupation of the pore by two $\mathrm{Cl}^{-}$ions. In the 6QVB-based CLC-2 ${ }^{\mathrm{CLC}-1}$ (redwood) E213 pointed to $\mathrm{Y} 561$ and was in close proximity with the backbone of 465GAF467 in 6QVU-based CLC-2 ${ }^{\text {CLC-1 }}$ (yellow).

Y561 and E213 are coupled to control CLC-2 gating. Some CLC-2 homology models showed E213 oriented away from Y561 suggesting that Y561 is unnecessary for gating, an idea echoed by a recent computational work aimed at determining CLC-2 fast gating ${ }^{32}$. However, in the CLC-2 6QVB model, E213 is facing Y561. This configuration is similar to that proposed for CLC-1 where the central Y578 residue participates in common gating $^{33}$. These observations led us to consider that E213 could interact with Y561 to control CLC-2 gating. To assess this idea, we produced single and double mutant channels replacing Y561 residue either by F or A, and the E213 residue by D to maintain the negative charge at this position but with a shortened side chain. The activity of wild type (WT) and mutant channels was measured using both patch-clamp and cut-open oocyte voltage-clamp. Figure 2A shows representative currents from WT, Y561F, Y561A, E213D, and E213D-Y561A channels using the voltage protocol depicted in the upper left part of the figure. Y561F channel presented a similar inwardly rectifying activation as the WT channel but showed faster activation kinetics. In contrast, the Y561A channel presented both inward and outward currents, supporting the idea that this residue is important for maintaining the closed state. Remarkably, voltage-activated currents through the Y561A channel were observed at positive and negative potentials. The currents activated fast but displayed a slow decay at positive voltages. If E213 interacts with Y561, then a residue with a shorter side chain at position 213 would disturb this interaction and affect the activation of the channel similarly. Indeed, E213D mutant channel displayed both inward and outward rectifying currents. The inward currents were like those observed in the WT channel whereas the outward currents exhibited a slow time course, tail currents were not observed at $+80 \mathrm{mV}$. The double mutant E213D-Y561A had currents like those of Y561A but with a larger instantaneous component.

Plots in the upper row of Fig. 2B show the voltage dependence of the apparent open probability $\left(\mathrm{P}_{\mathrm{A}}\right)$ for WT, Y561F, Y561A, E213D, and E213D-Y561A channels. The plots were fitted with a single or double Boltzmann function (Eq. 3) to determine the half-maximum activation voltage $\left(\mathrm{V}_{0.5}\right.$, in $\left.\mathrm{mV}\right)$ and the apparent charge $(\mathrm{z})$ quantifying their voltage dependence. The $\mathrm{V}_{0.5}$ values of Y561F, Y561A and E213D-Y561A mutants were rightward shifted $(>+54 \mathrm{mV})$ relative to $\mathrm{WT}$ whereas $\mathrm{z}$ remained between $-0.84(\mathrm{WT})$ and $-0.60(\mathrm{E} 213 \mathrm{D}-\mathrm{Y} 561 \mathrm{~A})$. $\mathrm{P}_{\mathrm{A}}$ of both Y561A and E213D-Y561A reached a minimum value of 0.2 at around $+80 \mathrm{mV}$ and then increased to about 0.4 at $+200 \mathrm{mV}$, a behaviour we referred to as re-opening (Fig. 2B, Table 1). Moreover, we determined that this reopening behaviour corresponds to currents flowing through CLC-2 channels since $5 \mathrm{mM} \mathrm{Zn^{2+ }}$, a blocker of CLC- $2^{34}$, effectively blocked both positive and negative currents of the Y561A channel (Supplementary Fig. 1). In contrast, $\mathrm{V}_{0.5} / \mathrm{z}$ values of $\mathrm{E} 213 \mathrm{D}$ were like those of $\mathrm{WT}:-92.4 \pm 1.4 \mathrm{mV} /-0.60 \pm 0.02 \mathrm{vs}$ $-89.3 \pm 8.5 \mathrm{mV} /-0.84 \pm 0.04$, respectively, and $\mathrm{P}_{\mathrm{A}}$ displayed a less pronounced re-opening at positive potentials. The voltage dependence of the apparent open probability of the pore $\left(\mathrm{P}_{\mathrm{P}}\right)$ and common $\left(\mathrm{P}_{\mathrm{C}}\right)$ gates of WT, Y561F, Y561A, E213D, and E213D-Y561A channels are shown in the lower row of Fig. 2B. Notably, in the Y561A, E213D, and E213D-Y561A channels, $P_{P}$ increased at positive potentials. Since $P_{C}$ remains partially open, the re-opening behaviour of $P_{P}$ explains the outward currents at positive voltages in these channels. Table 1 summarizes the $V_{0.5}$ and $\mathrm{z}$ values of $\mathrm{P}_{\mathrm{p}}$ and $\mathrm{P}_{\mathrm{C}}$ calculated from single or double Boltzmann fits (continuous lines) to the data. Like $\mathrm{P}_{\mathrm{A}}$, the $\mathrm{V}_{0.5}$ values for $\mathrm{P}_{\mathrm{P}}$ of Y561F, Y561A, and E213D-Y561A were rightward shifted by $>+40 \mathrm{mV}$ relative to WT without changing $z$.

In addition to the changes in voltage dependence and magnitude of $\mathrm{P}_{\mathrm{P}}$ above described the voltage dependence of $\mathrm{P}_{\mathrm{C}}$ of Y561F, Y561A, E213D, and E213D-Y561A mutant channels was also shifted to the right by $+60,+45,+25$, and $+48 \mathrm{mV}$, respectively. $\mathrm{P}_{\mathrm{C}}$ of the Y561A channel was slightly higher than that for WT, but it was close to zero in the E213D mutant. Similar results were obtained using the cut-open oocyte technique with the WT, Y561F, and Y561A channels (Supplementary Fig. 2 and Table 1). 
A

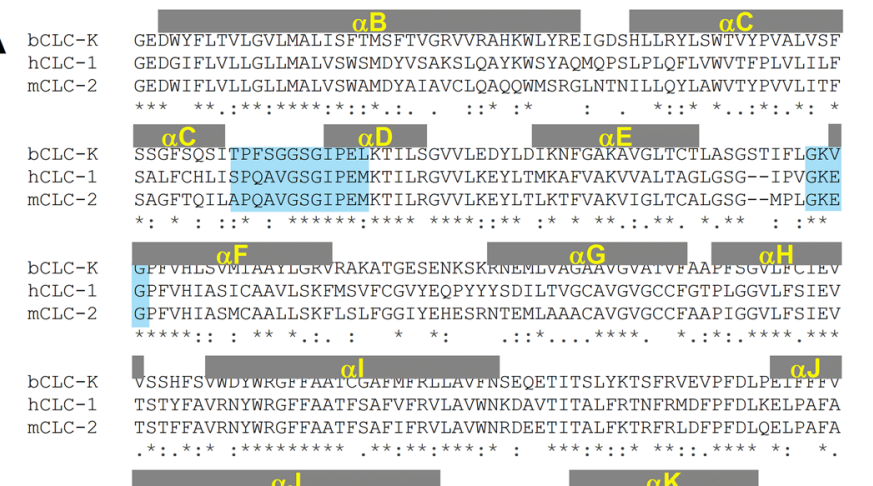

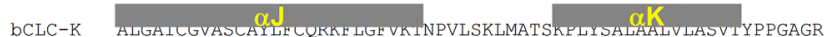
hCLC-1 AIGICCGLLGAVFVYLHROVMLGVRKHKALSQFLAKHRLLYPGIVTFVIASETFPPGMGQ mCLC-2 VIGIASGFGGALFVYLNRKIVQVMRKQKT INRFIMRKRLLFPALVTLLISTLTFPPGFGQ

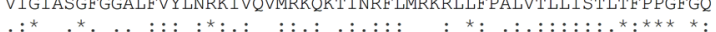

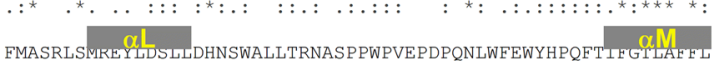
FMASRLSIMKEYLISLLDHNSWALLTRNASPPWPVEPDPQNLWFEWYHPQETTFGT LAFFL
FMAGELMPREAISTLFDNNTWVKHAG--DP------ESLGQSAVWIHPRVNVVI I IFLFF FMAGE LMPREAISTLFDNNTWVKHAG--DP-------ESLGQSAVWIHPRVNVVI IIFLFF
FMAGQLSQKETLVTLF DNRTWVRQGLVEDL-----ELPSTSQAWSPPRANVFLTLVIFI

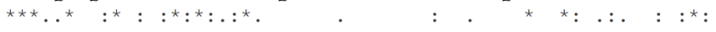

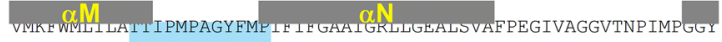
VMKFWMS IVATTMP I PCGGFMPVFVLGAAFGRLVGE IMAMLFPDGI LFDDI I YKI LPGGY LMKFWMSALATTIPVPCGAFMPVFVIGAAFGRLVGESMAAWFPDGIHTDSSTYRIVPGGY

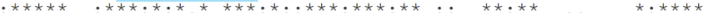

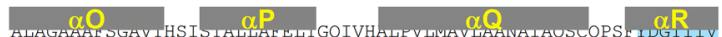
AVIGAAALTGAVSHTVSTAVICFELTGQIAHILPMMVAVI LANMVAQSLQPSLYDSI IQV AVVGAAALAGAVTHTVSTAVIVFELTGQIAHILPVMIAVILANAVAQSLQPSLYDSIIRI

$\begin{array}{lll}\text { bCLC-K } & \text { NKLPYLPWIRGRKI } & 540 \\ \text { hCLC-1 } & \text { KKLPYLPDLGWNOL } & 598\end{array}$

MCLC-2 KKLPYLPELGWGRH 581

C

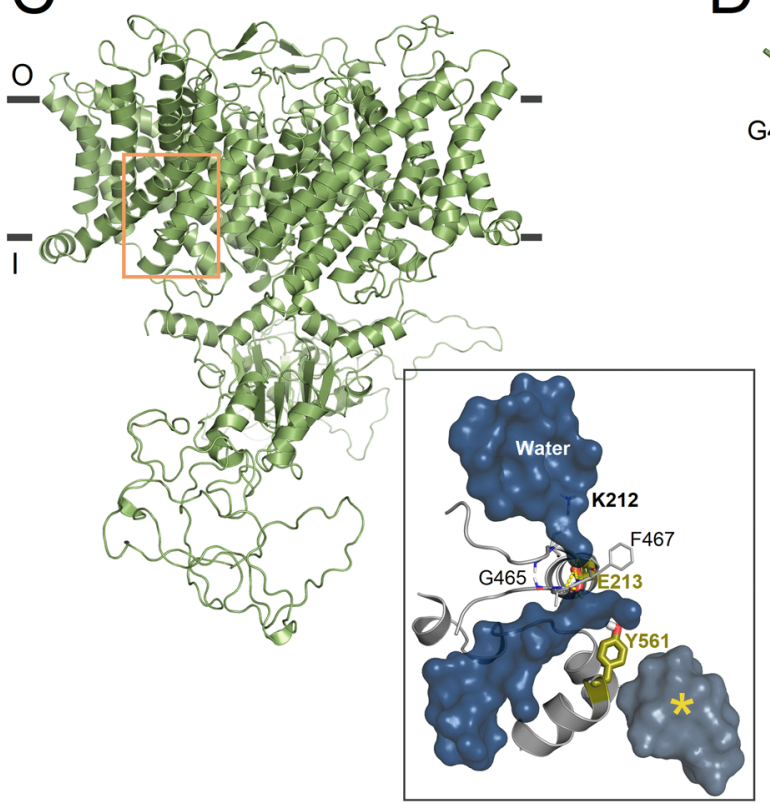

CLC-2 models merge
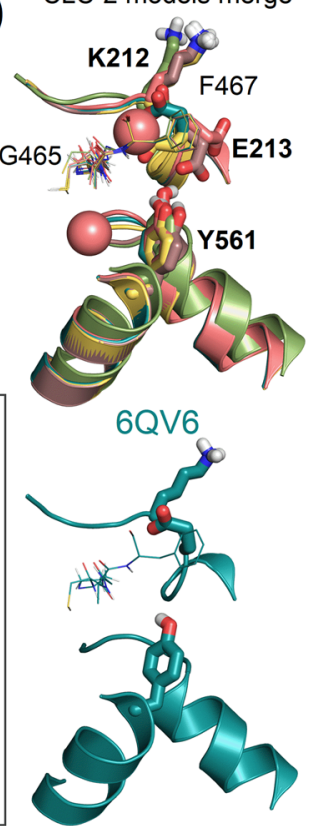

B

174 155
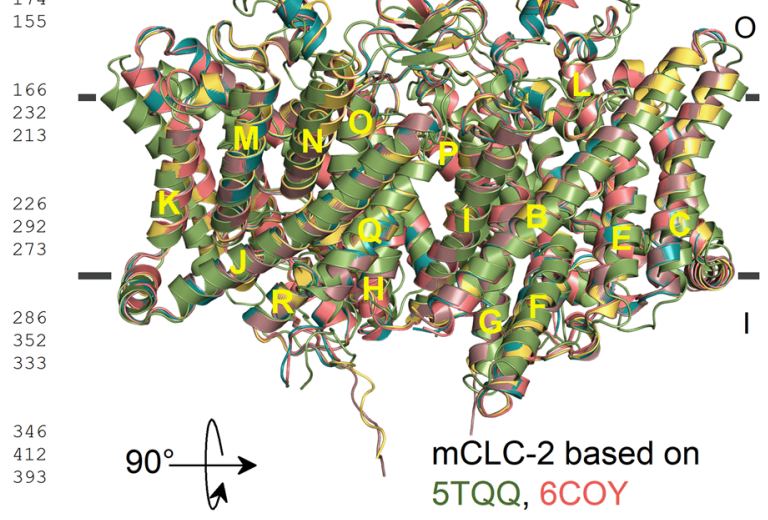

406 447

466 524

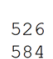
584

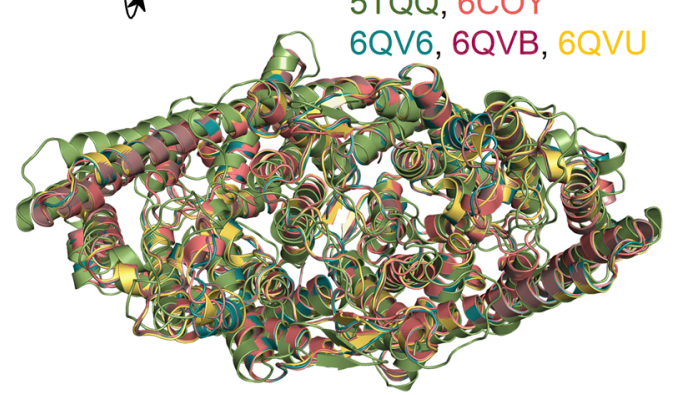

mCLC-2 based on

$5 T Q Q, 6 C O Y$

6QV6, 6QVB, 6QVU

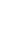
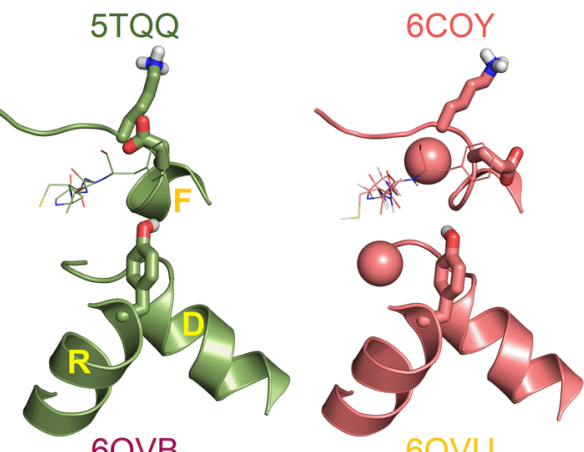

6QVB
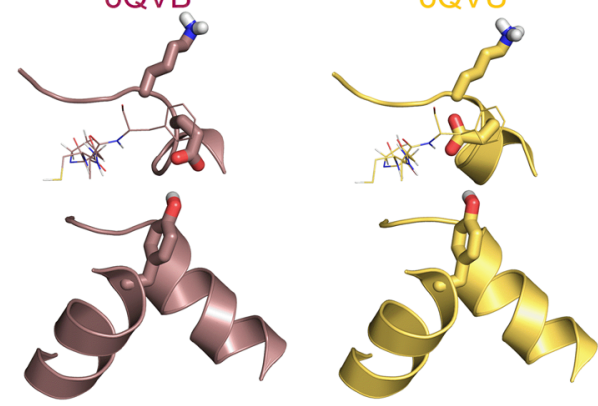

Figure 1. Homology models of the CLC-2 structure. (A) Sequence alignment of the transmembrane region of bovine CLC-K (bCLC-K), human CLC-1 (hCLC-1), and mouse CLC-2 (mCLC-2). Residues forming B-R alpha helices are shown in grey and pore region residues are highlighted in blue. (B) Structural alignment of the homology models for the CLC-2 structure. Homology structures were built using the cryo-EM structure of CLC-K (5TQQ, green) and hCLC-1 (6COY, salmon; 6QV6, cyan; 6QVB, redwood; $6 \mathrm{QVU}$, yellow) channels as templates. Views of the transmembrane domains (yellow letters) perpendicular to membrane plane (above) and from the top (below). Parallel grey lines indicate external (o) and internal (i) membrane limits. The RMSD of backbone atoms were $<0.31 \AA$ and the C-score $=1.98$ calculated by I-Tasser ( 2 is the upper limit). (C) mCLC-2 ${ }^{\mathrm{CLC}-\mathrm{K}}$ model structure showing the transmembrane and intracellular cystathionine- $\beta$-synthase (CBS) domains. The external and internal membrane limits are indicated by parallel grey lines. The orange square indicates the intracellular pore region shown in (D). Grey square shows the canonical pore flooded with water represented as a dark surface. The intracellular alternative pathway, unconnected to the canonical pore, is shown in grey marked with a yellow asterisk. Y561 and E213 are in olive. (D) Pore region of mCLC-2 models. Pore regions superposition (CLC-2 models merge) from homology structures. Sticks represent K212, E213, and Y561. The sidechain of E213 adopted different positions depending on the template; away from Y561 in 5TQQ, 6COY, and 6QV6 based models and closer to Y561 in 6QVB and 6QVU based models. Chloride ions (pink spheres) from hCLC-1 6COY were placed in the 6COY-based CLC-2 model. 

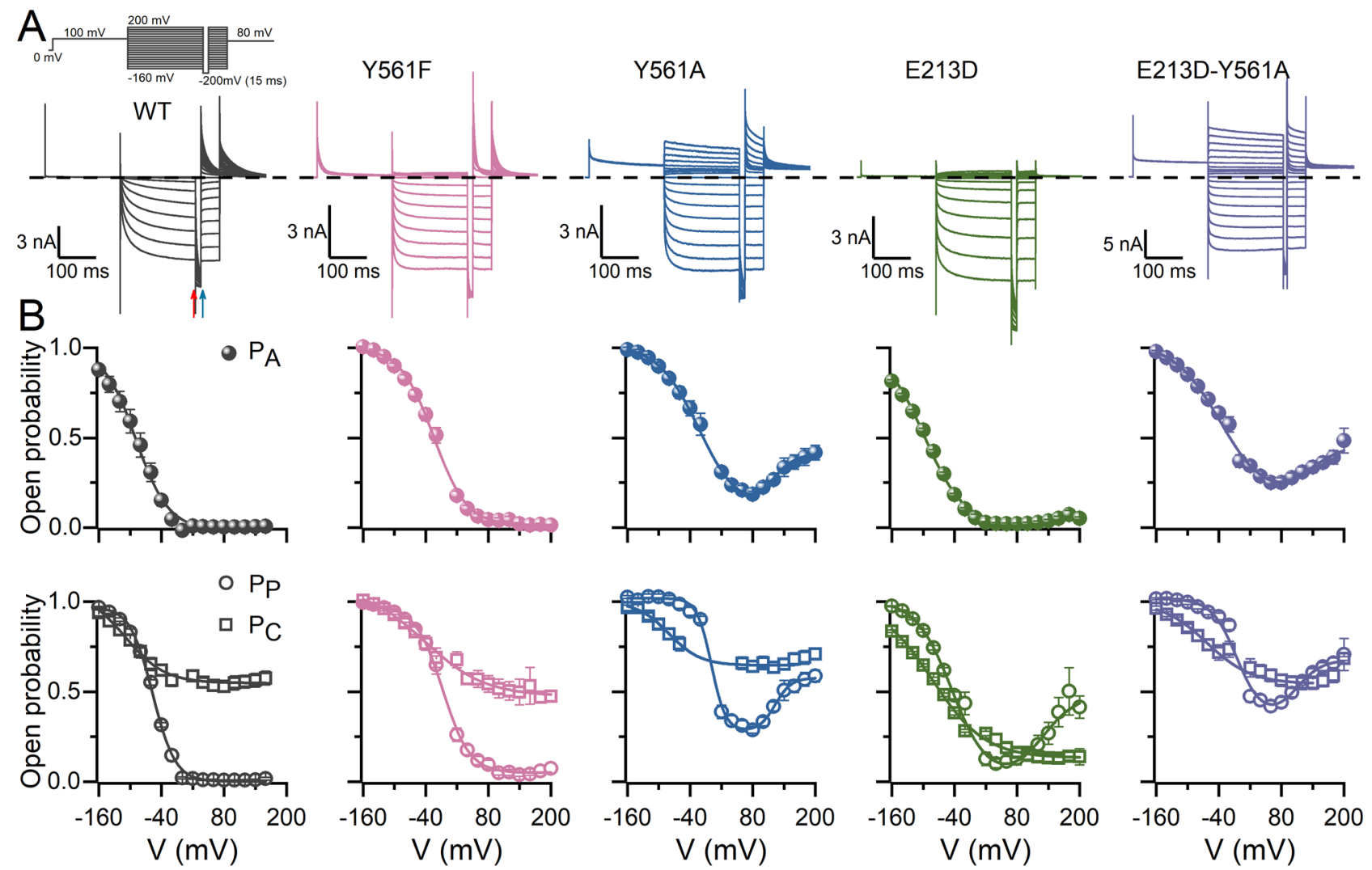

Figure 2. Voltage-dependent activation of CLC-2 depends on both Y561 and E213. (A) Colour coded $\mathrm{Cl}^{-}$currents recorded from five different HEK293 cells expressing WT CLC-2, Y561F, Y561A, E213D, and E213D-Y561A channels. $\mathrm{Cl}^{-}$currents were elicited by the voltage protocol shown in the upper left corner. The protocol consisted of voltage steps from -160 or -200 to $+200 \mathrm{mV}$ in $20 \mathrm{mV}$ increments and a repolarization voltage to $+80 \mathrm{mV}$ to record tail currents. We intercalated a $15 \mathrm{~ms} /-200 \mathrm{mV}$ step and used the magnitude of the currents measured before and after the interpulse (red and blue arrows, respectively) to calculate the open probability of pore $\left(\mathrm{P}_{\mathrm{P}}\right)$ and common $\left(\mathrm{P}_{\mathrm{C}}\right)$ gates (see methods). $\mathrm{Cl}^{-}$currents were recorded using $\mathrm{pH}_{\mathrm{i}}=\mathrm{pH}_{\mathrm{o}}=7.3$ and $\left[\mathrm{Cl}^{-}\right]_{\mathrm{i}}=\left[\mathrm{Cl}^{-}\right]_{\mathrm{o}}=140 \mathrm{mM}$. (B) The voltage dependency of the apparent open probability $\left(\mathrm{P}_{\mathrm{A}}\right.$, spheres), pore $\left(\mathrm{P}_{\mathrm{P}}\right.$ circles) and common $\left(\mathrm{P}_{\mathrm{C}}\right.$, squares) gates computed for WT CLC-2, Y561F, Y561A, E213D, and E213DY561A channels. Upper row: $\mathrm{P}_{\mathrm{A}}$; lower row: $\mathrm{P}_{\mathrm{P}}$ and $\mathrm{P}_{\mathrm{C}}$. Continuous lines are fits with a single $\left(\mathrm{P}_{\mathrm{A}}\right.$ of WT, Y561F, and E213D; $\mathrm{P}_{\mathrm{P}}$ of WT and Y561F; $\mathrm{P}_{\mathrm{C}}$ of all channels) or double $\left(\mathrm{P}_{\mathrm{A}}\right.$ of Y561A and E213D-Y561A; $\mathrm{P}_{\mathrm{P}}$ of Y561A, $\mathrm{E} 213 \mathrm{D}$, and E213D-Y561A) Boltzmann equation to determine voltage-dependent parameters $\mathrm{V}_{0.5}$ and $\mathrm{z}$ listed in Table 1.

The above data suggested that these mutations were altering both the pore and the common gates of CLC- 2 . We corroborated this idea by quantifying the fractional contribution of the fast $\left(\mathrm{W}_{\mathrm{p}}\right)$, slow $\left(\mathrm{W}_{\mathrm{c}}\right)$ and constant $\left(\mathrm{W}_{\text {const }}\right)$ components of the whole cell $\mathrm{Cl}^{-}$current, as well as their time constants $\left(\tau_{\mathrm{f}}\right.$ and $\left.\tau_{\mathrm{s}}\right)$ using a biexponential curve fit (Eq. 2) to the current recordings. Figure $3 \mathrm{~A}$ shows the contribution of $\mathrm{W}_{\mathrm{P}}$ (left), $\mathrm{W}_{\mathrm{C}}$ (middle) and $\mathrm{W}_{\text {const }}$ (right) to the whole cell currents generated by WT, Y561F, Y561A, E213D, and E213D-Y561A channels. $\mathrm{W}_{\mathrm{P}}$ associated with the fast gating decreased at negative potentials, whereas $\mathrm{W}_{\mathrm{C}}$ associated with the common gating decreased in the mutants at all voltages. $\mathrm{W}_{\text {const }}$ increased at all potentials in all mutants indicating that the open probability of the channels increased at all potentials. Figure $3 \mathrm{~B}$ shows the voltage dependence of the fast (closed symbols) and slow (open symbols) time constants for the currents generated by the WT, Y561F, Y561A, E213D, and E213D-Y561A channels. The fast time constants were between 1.5 and $10 \mathrm{~ms}$ whereas the slow time constants were between 20 and $100 \mathrm{~ms}$. Both time constants increased at depolarized voltages (Fig. 3B).

The double mutant cycle analysis and anomalous mole fraction behaviour reveal the interaction of Y561 and E213 in CLC-2. The previous data show that Y561 together with E213 keep the pore of CLC-2 closed. Furthermore, when Y561 is mutated, the common gate opening is facilitated and E213 can move in both outward and inward directions as indicated by the re-opening. These findings suggested that E213 and Y561 are interacting. Evidence for this idea was obtained by performing a double mutant cycle analysis ${ }^{35}$ and by determining the anomalous mole fraction (AMF) behaviour.

Double-mutant cycle analysis has been extensively applied to determine the interaction and its strength between pairwise residues ${ }^{36,37}$. We applied this thermodynamic analysis to determine whether E213 and Y561 are energetically coupled in the gating process of CLC- 2 . In the square in Fig. $4 \mathrm{~A}, \Delta\left(\mathrm{zFV}_{0.5}\right)_{1}, \Delta\left(\mathrm{zFV}_{0.5}\right)_{2}, \Delta\left(\mathrm{zFV}_{0.5}\right)_{3}$, 


\begin{tabular}{|c|c|c|c|c|c|c|c|c|c|c|c|}
\hline \multicolumn{2}{|l|}{ Channel } & $V_{0.5}^{P_{A}}(\mathrm{mV})$ & $z_{P_{A}}$ & $V_{0.5}^{P_{P}}(\mathrm{mV})$ & $z_{P_{P}}$ & $V_{0.5}^{P_{C}}(\mathrm{mV})$ & $z_{P_{C}}$ & $\operatorname{Er}(\mathrm{mV})$ & $\mathrm{pH}_{\mathrm{i}}$ & {$\left[\mathrm{Cl}^{-}\right]_{\mathrm{o}}(\mathrm{mM})$} & $\mathbf{n}$ \\
\hline \multicolumn{2}{|l|}{$\begin{array}{l}\text { WT } \\
\text { WT-OOC }\end{array}$} & $\begin{array}{l}-89.3 \pm 8.5 \\
-96.9 \pm 7.5\end{array}$ & $\begin{array}{l}-0.84 \pm 0.04 \\
-0.87 \pm 0.04\end{array}$ & $\begin{array}{l}-56.6 \pm 1.0 \\
-72.3 \pm 1.4\end{array}$ & $\begin{array}{l}-1.17 \pm 0.07 \\
-1.24 \pm 0.10\end{array}$ & $\begin{array}{l}-110.9 \pm 6.3 \\
-115.1 \pm 5.5\end{array}$ & $\begin{array}{l}-0.75 \pm 0.03 \\
-1.17 \pm 0.13\end{array}$ & $1.9 \pm 0.3$ & \begin{tabular}{|l|}
7.3 \\
7.3
\end{tabular} & $\begin{array}{l}140 \\
140 \\
\end{array}$ & $\begin{array}{l}5 \\
7\end{array}$ \\
\hline \multicolumn{2}{|l|}{ WT } & $-79.1 \pm 5.8$ & $-0.78 \pm 0.02$ & $-39.5 \pm 2.2$ & $-1.19 \pm 0.07$ & $-82.9 \pm 6.1$ & $-0.54 \pm 0.04$ & $57.4 \pm 0.6$ & 7.3 & 10 & 5 \\
\hline \multicolumn{2}{|l|}{$\begin{array}{l}\text { Y561F } \\
\text { Y561F-OOC }\end{array}$} & $\begin{array}{l}-34.8 \pm 9.4^{*} \\
-29.7 \pm 7.6\end{array}$ & $\begin{array}{l}-0.8 \pm 0.0 \\
-0.57 \pm 0.05\end{array}$ & $\begin{array}{l}-13.8 \pm 6.4^{*} \\
-5.66 \pm 9.9\end{array}$ & $\begin{array}{l}-1.1 \pm 0.1 \\
-0.71 \pm 0.05\end{array}$ & $\begin{array}{l}-51.2 \pm 6.4 \\
-37.3 \pm 17.9\end{array}$ & $\begin{array}{l}-0.4 \pm 0.0 \\
-0.62 \pm 0.1\end{array}$ & & \begin{tabular}{|l|}
7.3 \\
7.3
\end{tabular} & $\begin{array}{l}140 \\
140\end{array}$ & $\begin{array}{l}9 \\
7\end{array}$ \\
\hline \multicolumn{2}{|l|}{ Y561F } & $-68.9 \pm 5.4^{\dagger}$ & $-0.67 \pm 0.02$ & $-6.3 \pm 4.4$ & $-0.73 \pm 0.04^{\dagger}$ & $-71.9 \pm 4.5$ & $-0.62 \pm 0.07$ & $52.5 \pm 1.6$ & 7.3 & 10 & 6 \\
\hline \multirow{2}{*}{ Y561F } & $\mathrm{O}$ & $-36.0 \pm 5.1$ & $-0.68 \pm 0.03$ & $-19.7 \pm 2.1$ & $-0.95 \pm 0.08$ & $-36.1 \pm 7.9$ & $-0.53 \pm 0.06$ & & \multirow{2}{*}{5.5} & \multirow{2}{*}{140} & \multirow{2}{*}{8} \\
\hline & $\mathrm{rO}$ & $172.1 \pm 9.9$ & $0.76 \pm 0.10$ & $188.0 \pm 6.4$ & $-0.71 \pm 0.10$ & & & & & & \\
\hline \multirow{2}{*}{ Y561F } & $\mathrm{O}$ & $-58.6 \pm 18.8$ & $-0.69 \pm 0.09$ & $-21.1 \pm 8.6$ & $-1.09 \pm 0.17$ & $-78.7 \pm 23.2$ & $-0.63 \pm 0.06$ & & \multirow{2}{*}{4.3} & \multirow{2}{*}{140} & \multirow{2}{*}{5} \\
\hline & $\mathrm{rO}$ & $163.3 \pm 7.2$ & $0.98 \pm 0.14$ & $171.0 \pm 12.2$ & $0.83 \pm 0.11$ & & & & & & \\
\hline \multirow{2}{*}{ Y561A } & $\mathrm{O}$ & $-21.2 \pm 6.2^{*}$ & $-0.79 \pm 0.07$ & $5.1 \pm 2.8^{*}$ & $-1.25 \pm 0.02$ & $-65.6 \pm 10.6$ & $-0.81 \pm 0.06$ & & \multirow{2}{*}{7.3} & \multirow{2}{*}{140} & \multirow{2}{*}{7} \\
\hline & $\mathrm{rO}$ & $130.8 \pm 3.3$ & $1.20 \pm 0.08$ & $123.3 \pm 3.7$ & $1.28 \pm 0.07$ & & & & & & \\
\hline \multirow{2}{*}{ Y561A-OOC } & $\mathrm{O}$ & $-37.1 \pm 3.6$ & $-0.77 \pm 0.02$ & $-16.7 \pm 9.6$ & $-0.85 \pm 0.05$ & $-64.0 \pm 1.88$ & $-1.05 \pm 0.01$ & & \multirow{2}{*}{7.3} & \multirow{2}{*}{140} & \multirow{2}{*}{3} \\
\hline & $\mathrm{rO}$ & $89.4 \pm 5.5$ & $1.23 \pm 0.07$ & $82.0 \pm 5.3$ & $1.17 \pm 0.03$ & & & & & & \\
\hline \multirow{2}{*}{ Y561A } & $\mathrm{O}$ & $-58.7 \pm 9.2^{\ddagger}$ & $-0.58 \pm 0.01$ & $27.2 \pm 3.8^{\ddagger}$ & $-1.02 \pm 0.02$ & $-74.5 \pm 7.3$ & $-0.64 \pm 0.07$ & \multirow{2}{*}{$57.5 \pm 0.8$} & \multirow{2}{*}{7.3} & \multirow{2}{*}{10} & \multirow{2}{*}{6} \\
\hline & $\mathrm{rO}$ & $193.0 \pm 4.1^{\ddagger}$ & $0.89 \pm 0.10$ & $147.0 \pm 21.6$ & $0.56 \pm 0.06^{\ddagger}$ & & & & & & \\
\hline \multirow{2}{*}{ Y561A } & $\mathrm{O}$ & $-32.6 \pm 5.3$ & $-0.75 \pm 0.06$ & $-9.0 \pm 4.2$ & $-0.93 \pm 0.06$ & $-77.2 \pm 15.9$ & $-0.98 \pm 0.16$ & & \multirow{2}{*}{5.5} & \multirow{2}{*}{140} & \multirow{2}{*}{9} \\
\hline & $\mathrm{rO}$ & $137.8 \pm 11.6$ & $0.93 \pm 0.10$ & $111.5 \pm 12.46$ & $-0.77 \pm 0.08^{\ddagger}$ & & & & & & \\
\hline \multirow{2}{*}{ Y561A } & $\mathrm{O}$ & $-36.5 \pm 7.6$ & $-0.73 \pm 0.08$ & $-14.3 \pm 5.1^{*}$ & $-0.96 \pm 0.10$ & $-66.7 \pm 12.1$ & $-0.77 \pm 0.07$ & & \multirow{2}{*}{4.3} & 140 & 10 \\
\hline & $\mathrm{rO}$ & $126.0 \pm 5.6$ & $0.63 \pm 0.05$ & $100.4 \pm 6.5$ & $0.84 \pm 0.08^{*}$ & & & & & 140 & 10 \\
\hline & $\mathrm{O}$ & $-92.4 \pm 1.4$ & $-0.60 \pm 0.02$ & $-43.0 \pm 2.8$ & $-0.74 \pm 0.03$ & $-86.0 \pm 6.1$ & $-0.51 \pm 0.01$ & & & & \\
\hline E213D & $\mathrm{rO}$ & $194.6 \pm 18.2$ & $0.42 \pm 0.03$ & $209.0 \pm 19.6$ & $0.55 \pm 0.06$ & & & & 7.3 & 140 & 8 \\
\hline F213D_Y561A & $\mathrm{O}$ & $-35.4 \pm 4.1^{*}$ & $-0.67 \pm 0.03$ & $-5.6 \pm 1.5^{*}$ & $-1.11 \pm 0.10$ & $-63.3 \pm 9.4$ & $-0.61 \pm 0.05$ & & 73 & 144 & $7+7+3$ \\
\hline L215D-1501A & $\mathrm{rO}$ & $122.9 \pm 4.7$ & $1.09 \pm 0.09$ & $101.5 \pm 6.7$ & $1.06 \pm 0.06$ & & & & 1.5 & 140 & $r^{\prime}$ \\
\hline
\end{tabular}

Table 1. Effect of $\left[\mathrm{H}^{+}\right]_{\mathrm{i}}$ and $\left[\mathrm{Cl}^{-}\right]_{\mathrm{O}}$ on the voltage-dependent parameters of WT and mutants CLC-2 channels. $\mathrm{V}_{0.5}^{\mathrm{P}_{\mathrm{A}}}=$ voltage to reach an open probability of $0.5, \mathrm{z}_{\mathrm{P}_{\mathrm{A}}}=$ apparent charge of the open-closed transition, $\mathrm{V}_{0.5}^{\mathrm{P}_{\mathrm{P}}}=$ voltage to reach a 0.5 open probability of $\mathrm{Glu}_{\text {gate, }}, \mathrm{z}_{\mathrm{P}_{\mathrm{P}}}=$ apparent charge of the $\mathrm{Glu}_{\text {gate }}, \mathrm{V}_{0.5}^{\mathrm{P}_{\mathrm{C}}}=$ voltage to reach a 0.5 open probability of the common gate, $\mathrm{ZP}_{\mathrm{C}}=$ apparent charge the common gate. These parameter values were calculated by fitting the data to the Boltzmann equation (Eq. 3). Er = reversal potentials determined by current-voltage relationship interpolations. Data were collected from HEK 293 cells and from cut-open oocytes (OOC). Within a column, those mean values labelled with ${ }^{\star}, \dagger$, or $\ddagger$ were statistically different to that of to WT, Y561A, or Y561F, respectively. Reference values of to WT, Y561A, and Y561F were calculated from recording obtained under control conditions $\left(\mathrm{pH}_{\mathrm{i}}=\mathrm{pH}_{\mathrm{e}}=7.3\right.$ and $\left.\left[\mathrm{Cl}^{-}\right]_{\mathrm{i}}=\left[\mathrm{Cl}^{-}\right]_{\mathrm{e}}=140 \mathrm{mM}\right)$. Mean values were compared using a one-way ANOVA with a Tukey post hoc test with $\mathrm{p}<0.01$.
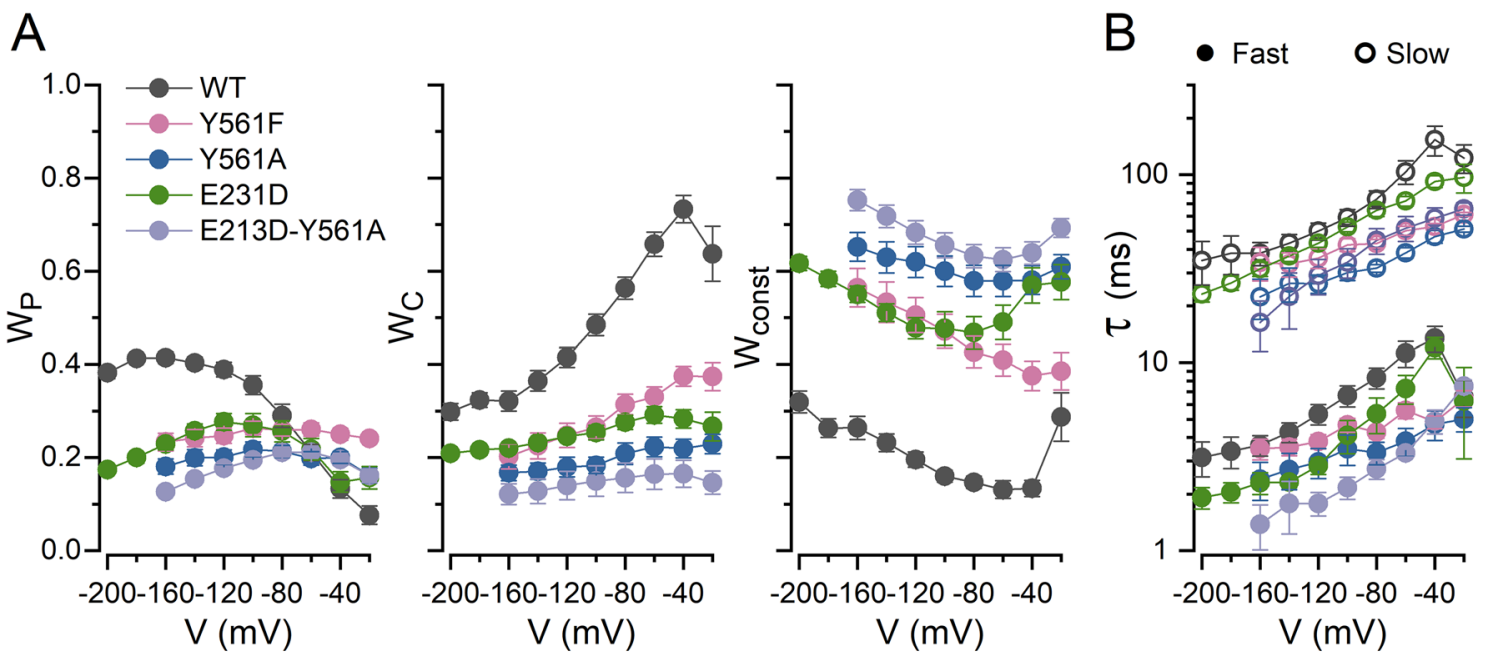

Figure 3. Kinetics analysis of $\mathrm{WT}$ and $\mathrm{Y} 561$ and E213 mutant channels. (A) The relative contribution of fast $\left(\mathrm{W}_{\mathrm{P}}\right)$, slow $\left(\mathrm{W}_{\mathrm{C}}\right)$ and constant $\left(\mathrm{W}_{\text {const }}\right)$ components of the total $\mathrm{Cl}^{-}$current generated by the colour coded indicated channels. (B) Voltage dependence of fast ( $\tau_{\mathrm{f}}$, closed circles) and slow ( $\tau_{\mathrm{s}}$, open circles) time constants of the $\mathrm{Cl}^{-}$currents generated by the channels indicated in (A). Whole cell $\mathrm{Cl}^{-}$currents were fitted with a biexponential function (Eq. 2) to determine $\mathrm{W}_{\mathrm{p}}, \mathrm{W}_{\mathrm{C}}, \mathrm{W}_{\text {const }}, \tau_{\mathrm{f}}$, and $\tau_{\mathrm{s}}$. 
A

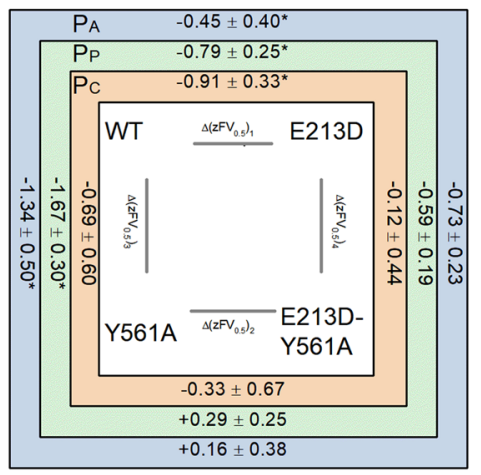

B

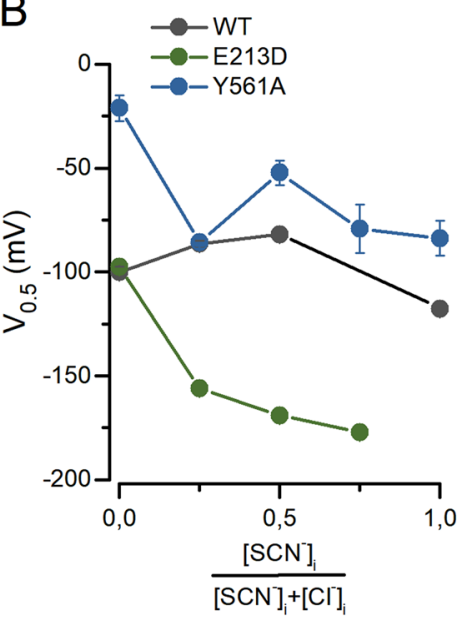

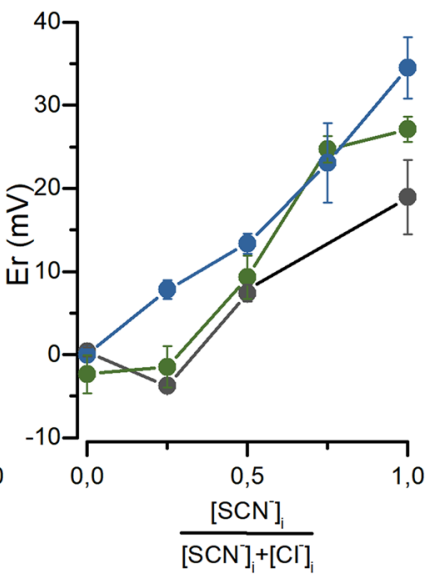

E

C
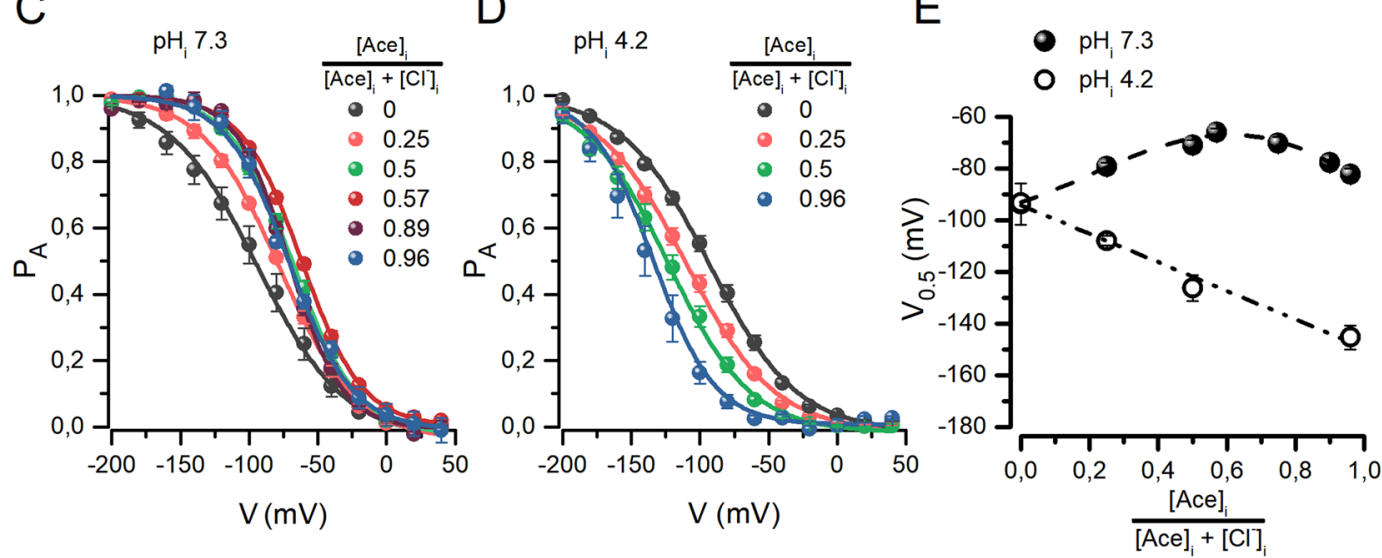

Figure 4. Double mutant cycle analysis and anomalous mole fraction behaviour show coupling of E213 and Y561. (A) Double mutant cycle analysis. The analysis was performed using the $\mathrm{z}$ and $\mathrm{V}_{0.5}$ obtained for $\mathrm{P}_{\mathrm{A}}$ (blue square), $\mathrm{P}_{\mathrm{P}}$ (green square), and $\mathrm{P}_{\mathrm{C}}$ (orange square) for the WT, E213D, Y56A and E213D-Y561A channels listed in Table 1. $\Delta\left(\mathrm{zFV}_{0.5}\right)_{1}, \Delta\left(\mathrm{zFV}_{0.5}\right)_{2}, \Delta\left(\mathrm{zFV}_{0.5}\right)_{3}$, and $\Delta\left(\mathrm{zFV}_{0.5}\right)_{4}$ are the energy change in the voltage-dependent gating caused by a given mutation calculated using Eq. (1). For example, $\Delta\left(\mathrm{zFV}_{0.5}\right)_{1}$ is the energy change induced by mutating E213 in the WT CLC-2. The listed energy change values are in $\mathrm{kCal} / \mathrm{mol}$. The asterisks indicate statistically significant different pair $\Delta\left(\mathrm{zFV}_{0.5}\right)_{1}: \Delta\left(\mathrm{zFV}_{0.5}\right)_{2}$ and $\Delta\left(\mathrm{zFV}_{0.5}\right)_{3}: \Delta\left(\mathrm{zFV}_{0.5}\right)_{4}$ values. (B) Anomalous mole fraction behaviour of the voltage-dependent activation and reversal potential of WT $(n=5-9)$, E213D $(\mathrm{n}=6-10)$, and Y561A $(\mathrm{n}=4-7)$ channels. AMF behaviour was evaluated using $\mathrm{SCN}^{-} / \mathrm{Cl}^{-}$mixtures. $\mathrm{V}_{0.5}$ values were calculated using the Boltzmann equation to fit the negative portion of the curves whereas Er was calculated by interpolation in the current-voltage relationships. At $\mathrm{SCN}^{-}$mole fraction $=1$, we could not determine $\mathrm{E} 213 \mathrm{D}$ $\mathrm{V}_{0.5}$ (C,D) Voltage-dependent activation determined at pHi of $7.3(\mathrm{n}=5-10)$ and $4.2(\mathrm{n}=5-7)$ using different acetate mole fractions. $\mathrm{P}_{\mathrm{A}}$ was calculated using the tail current magnitude. The resulting curves were normalized to their respective tail current maximum obtained after fitting curves with the Boltzmann equation. Continuous lines are fits from which the voltage-dependent parameters $\mathrm{V}_{0.5}$ and $\mathrm{z}$ were computed. (E) $\mathrm{V}_{0.5}$ plotted against acetate mole fractions. Filled symbols correspond to data obtained at $\mathrm{pH}_{\mathrm{i}} 7.3$ whereas open symbols were collected at $\mathrm{pH}_{\mathrm{i}}$ 4.2. $\mathrm{V}_{0.5}$ values were obtained from Boltzmann fits to data shown in panels $\mathrm{C}$ and $\mathrm{D}$.

and $\Delta\left(\mathrm{zFV}_{0.5}\right)_{4}$ are the energy change (in $\mathrm{kCal} / \mathrm{mol}$ ) in gating caused by a given mutation. These energy changes were calculated ${ }^{37}$ as:

$$
\Delta\left(z F V_{0.5}\right)=-F\left(z_{W T} V_{0.5, W T}-z_{m u t} V_{0.5, m u t}\right)
$$

where $z_{W T}, z_{m u t}, V_{0.5, W T}$ and $V_{0.5, m u t}$ are the apparent charges and the half-maximum activating voltages of the WT and mutant channels listed in Table 1 . This analysis was performed for triplicated using the $\mathrm{z}$ and $\mathrm{V}_{0.5}$ values determined at negative voltages for $\mathrm{P}_{\mathrm{A}}, \mathrm{P}_{\mathrm{P}}$, or $\mathrm{P}_{\mathrm{C}}$ of WT, Y561A, E213D, and E213D-Y561A channels (colour coded in Fig. $4 \mathrm{~A})$. The mean $( \pm \mathrm{SD})$ values for $\Delta\left(\mathrm{zFV}_{0.5}\right)_{1}, \Delta\left(\mathrm{zFV}_{0.5}\right)_{2}, \Delta\left(\mathrm{zFV}_{0.5}\right)_{3}$, and $\Delta\left(\mathrm{zFV}_{0.5}\right)_{4}$ are shown. To infer whether E213 and Y561 are coupled we compared the energy changes induced by mutating E213 in the WT and the Y561A mutant channel. If mutating E213 induces the same change on the voltage dependence of WT and Y561A, then the energy changes should be the same regardless of the background used to make the mutation, that is $\Delta\left(\mathrm{zFV}_{0.5}\right)_{1}=\Delta\left(\mathrm{zFV}_{0.5}\right)_{2}$. However, if the voltage dependence of gating is altered differently in 
WT and Y561A, then $\Delta\left(\mathrm{zFV}_{0.5}\right)_{1}$ will be different to $\Delta\left(\mathrm{zFV}_{0.5}\right)_{2}$ implying that E213 and Y561 are coupled ${ }^{37}$. We statistically compared the pair values $\Delta\left(\mathrm{zFV}_{0.5}\right)_{1}: \Delta\left(\mathrm{zFV}_{0.5}\right)_{2}$ and $\Delta\left(\mathrm{zFV}_{0.5}\right)_{3}: \Delta\left(\mathrm{zFV}_{0.5}\right)_{4}$ listed in Fig. $4 \mathrm{~A}$. Of these pairs, only $\Delta\left(\mathrm{zFV}_{0.5}\right)_{3}$ and $\Delta\left(\mathrm{zFV}_{0.5}\right)_{4}$ within the $\mathrm{P}_{\mathrm{C}}$ cycle were not statistically different. In addition, using the $\Delta\left(\mathrm{zFV}_{0.5}\right)_{1}$ and $\Delta\left(\mathrm{zFV}_{0.5}\right)_{2}$ values calculated using the voltage-dependent parameters of $\mathrm{P}_{\mathrm{P}}$ (green square), we obtained that the $\Delta\left(\mathrm{zFV}_{0.5}\right)_{2}-\Delta\left(\mathrm{zFV}_{0.5}\right)_{1}=+1.08 \mathrm{kCal} / \mathrm{mol}$, a value that is different from 0 . Overall, this analysis indicates that Y561 and E213 are energetically coupled.

We previously showed that the voltage dependence of CLC-2, measured by $\mathrm{V}_{0.5}$, displays AMF behaviour in cells dialyzed with $\mathrm{SCN}^{-}$mole fractions ${ }^{15}$. Hence, if the anions are disturbing the Y561-E213 interaction responsible for voltage dependence gating of CLC-2 then the AMF behaviour of the voltage dependence will be altered in channels with these mutated residues. We determined the $\mathrm{V}_{0.5}$ of the WT, E213D, and Y561A channels exposed to $\mathrm{SCN}^{-} / \mathrm{Cl}^{-}$mixtures from the cytosolic side. Figure $4 \mathrm{~B}$ shows the relationship between $\mathrm{V}_{0.5}$ and $\mathrm{SCN}^{-}$mole fractions. The voltage dependence of the WT channel (black) displayed a concave relationship. However, the AMF behaviour of E213D $\mathrm{V}_{0.5}\left(4 \mathrm{~B}\right.$, green) was absent; as the $\mathrm{SCN}^{-}$mole fraction increased, $\mathrm{V}_{0.5}$ became more negative, albeit is a non-linear fashion. Y561A (Fig. 4B, blue), in contrast, showed $\mathrm{V}_{0.5}$ values that tended to be less negative than those determined for WT channels. However, in both mutants, the reversal potential increased as $\mathrm{SCN}^{-}$mole fraction increased; with $\mathrm{SCN}^{-}$mole fraction $=1$, the reversal potentials of these mutant currents were more positive than that of WT (Fig. 4B, right) suggesting that the $\mathrm{SCN}^{-}$permeability is altered. The singlechannel $\mathrm{Cl}^{-}$current of Y561A determined by noise analysis $(-0.26 \pm 0.01 \mathrm{pA}$ at $-100 \mathrm{mV}, \mathrm{n}=6)$ was similar to $\mathrm{WT}(0.23 \pm 0.02 \mathrm{pA}$ at $+100 \mathrm{mV}, \mathrm{n}=5)$ and the single-channel current of human CLC-2 at $-100 \mathrm{mV}(-0.23 \pm 0.02$ $\mathrm{pA})^{38}$ indicating that the single-channel conductance is not altered in this mutant. The AMF behaviour of WT CLC-2 was also observed with internal solutions containing acetate/ $\mathrm{Cl}^{-}$mole-fractions at $\mathrm{pH} 7.3$ (Fig. $4 \mathrm{C}, \mathrm{E}$ ). Then, we reduced the acetate negative charge by lowering the internal solutions $\mathrm{pH}$ to 4.2 ( $\mathrm{pK}$ of acetate $=4.75$; uncharged fraction $=0.22$ ) to study its effect on the voltage gating. Under this condition, increasing the acetate mole fraction shifted the voltage-dependent activation curves towards negative voltages (Fig. 4D). $\mathrm{V}_{0.5}$ had a linear relationship with acetate/ $\mathrm{Cl}^{-}$mole-fractions (Fig. $4 \mathrm{E}$, open circles) as in cells dialyzed only with $\mathrm{Cl}^{-15}$. Together these data support the idea that CLC-2 voltage gating is controlled by coupled Y561-E213 forming the gate that is opened by repulsion when the permeant anions occupy the pore.

Mutating Y561 renders sensitivity to extracellular $\mathrm{Cl}^{-}$and intracellular $\mathrm{H}^{+}$. A hallmark of CLC-2 gating is its remarkably low sensitivity to extracellular $\left[\mathrm{Cl}^{-}\right]\left(\left[\mathrm{Cl}^{-}\right]_{\mathrm{o}}\right)$ and intracellular $\left[\mathrm{H}^{+}\right]\left(\left[\mathrm{H}^{+}\right]_{\mathrm{i}}\right)^{15}$. The reopening observed at the positive voltage in the Y561A mutant channel suggested that gating occurred at both negative and positive voltages and that E213 is unconstrained and able to swing in the outward and inward directions. We wondered if $\mathrm{Cl}^{-}$influx would knock-in E213, just like the $\mathrm{Cl}^{-}$efflux knocks-out the E213 gate in the WT CLC-2 channel, thus inducing E213 re-opening at positive potentials. To assess this idea, we lowered the $\left[\mathrm{Cl}^{-}\right]_{\mathrm{o}}$ from 140 to $10 \mathrm{mM}$. Decreasing the $\mathrm{Cl}^{-}$influx had little effect on the kinetics of WT, Y561F and Y561A currents (black vs. blue traces in Fig. 5A-C). In the WT channel, the voltage dependence of $\mathrm{P}_{\mathrm{A}}$ and $\mathrm{P}_{\mathrm{P}}$ were not affected (Fig. 5A, Table 1). However, in Y561F mutant channels (Fig. 5B), the $\mathrm{V}_{0.5}$ of $\mathrm{P}_{\mathrm{A}}$ was shifted by $-34 \mathrm{mV}$, whereas the effect on $\mathrm{P}_{\mathrm{P}}$ was negligible (Table 1). Interestingly, the reopening previously observed in the Y561A mutant channel was abolished by lowering the extracellular $\mathrm{Cl}^{-}$(Fig. $5 \mathrm{C}$ ). $\mathrm{P}_{\mathrm{A}}$ was shifted by about $-37 \mathrm{mV}$ and $\mathrm{P}_{\mathrm{P}}$ diminished from 0.3 to 0.1 at positive voltages. This indicates that decreasing the $\mathrm{Cl}^{-}$influx diminishes the reopen probability of E213 at positive potentials in the Y561A mutant channel, suggesting that Y561 participates in the stability of the closed state through E213. Under low $\left[\mathrm{Cl}^{-}\right]_{0}$ conditions, $\mathrm{P}_{\mathrm{C}}$ was nearly equally diminished with little effects on $\mathrm{V}_{0.5}$ in all channels (Table 1).

Lowering $\mathrm{pH}_{\mathrm{i}}$ from 7.3 to 4.2 did not affect the voltage-dependent activation of WT CLC-2 (Fig. 6A); this result emphasises the fact that intracellular $\mathrm{H}^{+}$does not participate in WT CLC-2 activation. However, the effect of extracellular $\mathrm{Cl}^{-}$on Y561A mutant suggests that E213 can be pushed inwardly by the $\mathrm{Cl}^{-}$influx to induce channel re-opening. The opening of E213 in the inward direction could render it sensitive to intracellular $\mathrm{H}^{+}$. The Y561 mutant channels showed marked sensitivity to $\left[\mathrm{H}^{+}\right]_{\mathrm{i}}$ (Fig. 6B,C). Y561A channels showed larger currents than $\mathrm{Y} 561 \mathrm{~F}$ channels at positive potentials, after intracellular acidification (Fig. 6B,C). Decreasing $\mathrm{pH}_{\mathrm{i}}$ from 5.5 to 4.3 shifted the $\mathrm{P}_{\mathrm{A}}$ of both $\mathrm{Y} 561 \mathrm{~F}$ and Y561A by +23 and $+7 \mathrm{mV}$, respectively (Table 1 ). Notably, the minimum Y561A $\mathrm{P}_{\mathrm{A}}$ increased from 0.2 to nearly 0.6 after decreasing $\mathrm{pH}_{\mathrm{i}}$ from 7.3 to 4.3 (Fig. 6C). Similar effects were observed in the voltage dependence of E213, described by $\mathrm{P}_{\mathrm{P}}$, in the Y561F and Y561A channels (Fig. 6B,C, middle panels). At $\mathrm{pH}_{\mathrm{i}}$ 4.3, E213 reopened in $\mathrm{Y} 561 \mathrm{~F}$, whereas in $\mathrm{Y} 561 \mathrm{~A}$ it showed a substantial increment on the activation at $\mathrm{pH}_{\mathrm{i}} 5.5$ and 4.3. $\mathrm{P}_{\mathrm{P}}$ reached a minimum value of about 0.7 at positive voltages indicating that E213 remains almost fully open all the time. Despite these results, the $V_{0.5}$ of $P_{P}$ measured in the negative range of voltages remained unchanged in both mutants (Table 1). Intracellular acidification also changed the magnitude and shifted the voltage dependence of the $\mathrm{P}_{\mathrm{C}}$ towards negative voltages (Table 1). Taken together, these data show that intracellular acidification does not alter the voltage-gating of WT CLC-2, however, CLC-2 became sensitive to intracellular $\mathrm{H}^{+}$once Y561 is mutated. We think that Y561 holds E213 in the closed position and shields it from intracellular $\mathrm{H}^{+}$which would explain why intracellular acidification has no effects on WT CLC-2 gating ${ }^{16,21,23}$.

\section{Discussion}

In this work, we demonstrate that both E213 and Y561 residues keep the CLC-2 chloride channel closed and we propose that permeant anions can open the gate by an electro-steric mechanism. The mutation analysis of the homology structure of CLC-2 suggested that a two-leaf gate formed by Y561-E213 closes the pore of CLC-2. Mutating either of these residues decreased the fractional contribution of the fast and slow components of gating, associated with the protopore and common gates, respectively. Also, the double mutant analysis showed that Y561 and E213 are energetically coupled. Thus, the gate of CLC-2 is formed by the interaction of the common 


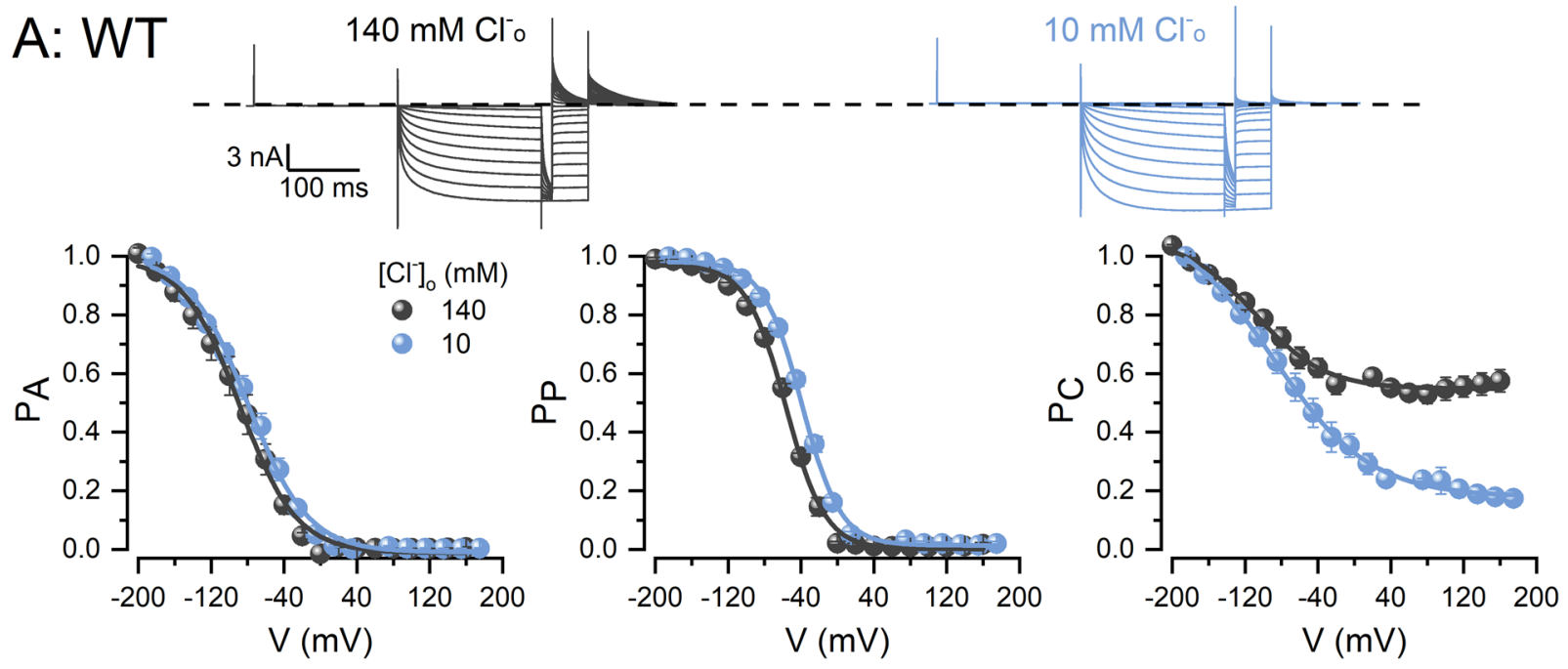

B: Y561F
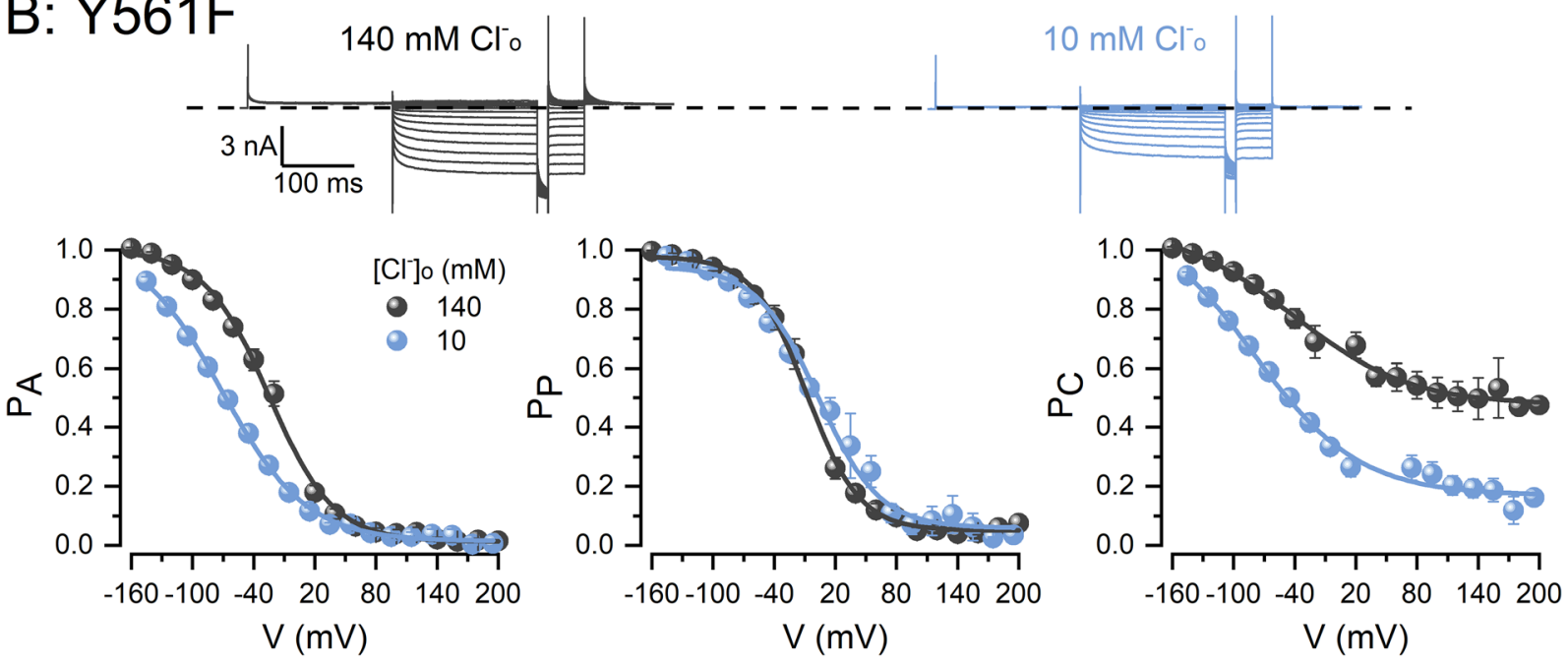

C: Y561A

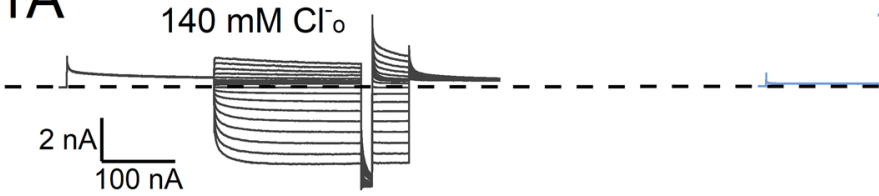

$10 \mathrm{mM} \mathrm{Cl}^{-} \mathrm{o}$
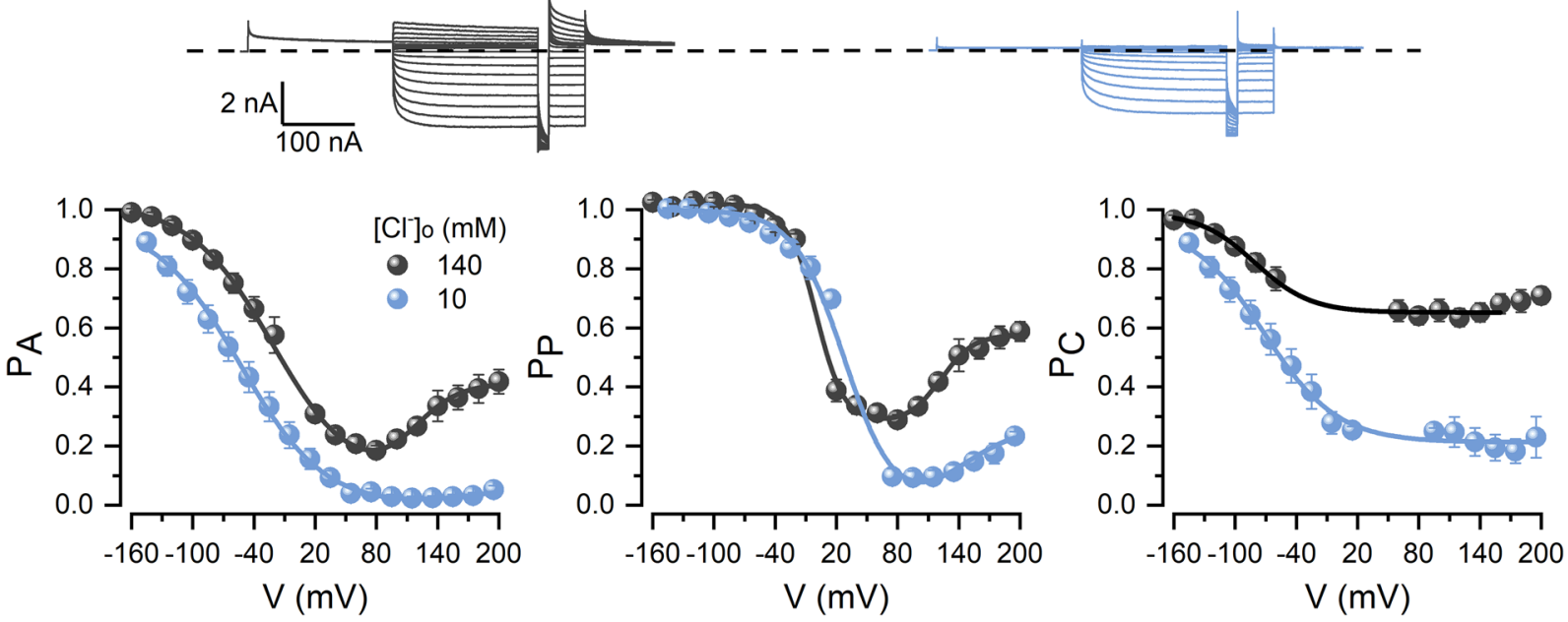

Figure 5. Y561F and Y561A CLC-2 mutant channels are sensitive to extracellular chloride. (A-C) Top panels: $\mathrm{Cl}^{-}$ currents recorded from HEK293 cells expressing WT CLC-2 (A), Y561F (B), or Y561A (C) exposed first to 140 (grey) and then 10 (blue) $\mathrm{mM}\left[\mathrm{Cl}^{-}\right]_{\mathrm{o}} \cdot\left[\mathrm{Cl}^{-}\right]_{\mathrm{i}}=140 \mathrm{mM}$ and $\mathrm{pH}_{\mathrm{i}}=\mathrm{pH}_{\mathrm{o}}=7.3$. Channels were activated using the voltage protocol shown in Fig. 2A. (A-C) Bottom panels: Voltage dependence of $\mathrm{P}_{\mathrm{A}}$ (left), $\mathrm{P}_{\mathrm{P}}$ (middle), and $\mathrm{P}_{\mathrm{C}}$ (right) for WT CLC-2 (A), Y561F (B) and Y561 A (C) determined first with 140 (grey) and then with 10 (blue) $\mathrm{mM}\left[\mathrm{Cl}^{-}\right]_{\mathrm{o}}$. $\left[\mathrm{Cl}^{-}\right]_{\mathrm{i}}=140 \mathrm{mM}$ and $\mathrm{pH}_{\mathrm{i}}=\mathrm{pH}_{\mathrm{o}}=7.3$. Lines are fits of the data with a single $\left(\mathbf{A}, \mathbf{B}\right.$, and $\mathrm{P}_{\mathrm{A}}$ from $10 \mathrm{mM} \mathrm{Cl}^{-}$data and $\mathrm{P}_{\mathrm{C}}$ in $\left.\mathbf{C}\right)$ or double $\left(\mathrm{P}_{\mathrm{A}}\right.$ from $140 \mathrm{mM} \mathrm{Cl}^{-}$data and $\mathrm{P}_{\mathrm{P}}$ in $\mathrm{C}$ ) Boltzmann equation. Voltage-dependent parameters $\mathrm{V}_{0.5}$ and $\mathrm{z}$ are listed in Table 1. 

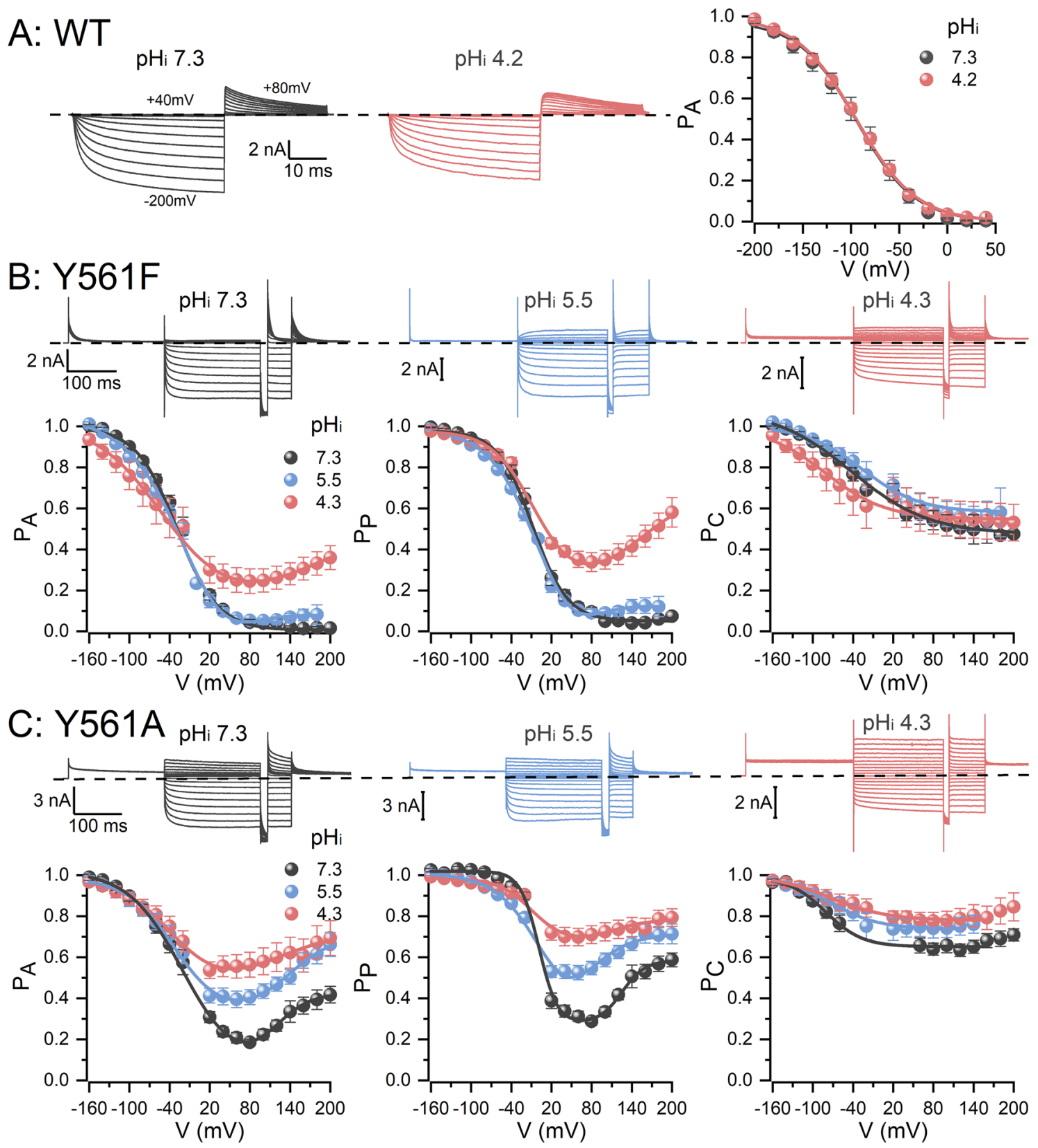

Figure 6. Y561F and Y561A CLC-2 mutant channels are sensitive to intracellular protons. (A) Intracellular acidification did not alter the voltage dependence of WT CLC-2 $\mathrm{P}_{\mathrm{A}}$. Recordings like those shown on the left side were analysed to construct $\mathrm{P}_{\mathrm{A}}$ vs $\mathrm{V}$ relations at $\mathrm{pH}_{\mathrm{i}}$ of 7.3 (grey) and 4.2 (red). The voltage-dependent parameters $\mathrm{V}_{0.5}$ were $-93.9 \pm 7.9 \mathrm{mV}$ and $-93.4 \pm 3.4 \mathrm{mV}$, at $\mathrm{pH}_{\mathrm{i}} 7.3$ and 4.2 , respectively $(\mathrm{n}=5)$. $(\mathbf{B}, \mathbf{C})$ Top panels. $\mathrm{Cl}^{-}$currents from three different HEK293 cells expressing the Y561F (B) or Y561A (C) mutants were recorded in the presence of $140 \mathrm{mM}$ intracellular $\mathrm{Cl}^{-}$and intracellular $\mathrm{pH} 7.3$ (grey), 5.5 (blue), 4.3 (red). The voltage protocol showed in Fig. 2A was utilized in these experiments. Extracellular $\mathrm{pH}$ and $\left[\mathrm{Cl}^{-}\right]_{0}$ were 7.3 and $140 \mathrm{mM}$, respectively. (B,C) Bottom panels. Voltage dependence of $\mathrm{P}_{\mathrm{A}}, \mathrm{P}_{\mathrm{P}}$ and $\mathrm{P}_{\mathrm{C}}$ for Y561F (B) and Y561A (C) are plotted using data collected at $\mathrm{pH}_{\mathrm{i}} 7.3$ (grey), 5.5 (blue) and 4.3 (red). Lines in (A-C) plots are fits of the data with a single $\left(\mathrm{P}_{\mathrm{A}}\right.$ in $\mathbf{A} ; \mathrm{P}_{\mathrm{A}}$ and $\mathrm{P}_{\mathrm{P}}$ at $\mathrm{pH}_{\mathrm{i}} 7.3$ and 5.5 and $\mathrm{P}_{\mathrm{C}}$ in $\mathbf{B} ; \mathrm{P}_{\mathrm{C}}$ in $\left.\mathbf{C}\right)$ or double $\left(\mathrm{P}_{\mathrm{A}}\right.$ and $\mathrm{P}_{\mathrm{P}}$ at $\mathrm{pH}_{\mathrm{i}} 4.3$ in $\mathbf{B} ; \mathrm{P}_{\mathrm{A}}$ and $\mathrm{P}_{\mathrm{P}}$ in $\mathrm{C}$ ) Boltzmann equation used to calculate $\mathrm{V}_{0.5}$ and $\mathrm{z}$ parameters listed in Table 1.

and protopore gates, as reported for CLC- $1^{33}$. Furthermore, these mutations facilitated the opening at negative potentials and the re-opening at positive voltages. We reasoned that E213 is decoupled from Y561 in the Y561A mutant channel, thus it is free to swing in the outward and inward directions guided by the $\mathrm{Cl}^{-}$flux direction. This idea is supported by the experiments performed under low external $\mathrm{Cl}^{-}$or high intracellular $\mathrm{H}^{+}$concentrations. Our proposal that both common and protopore gate participate in CLC-2 gating is in agreement with previous findings showing that these gates are coupled in this channel ${ }^{27}$. Interestingly, in CLC-0 and CLC-1 the same pair of residues participate in voltage gating ${ }^{33}$ and pore and common gating mechanisms have been suggested to be 


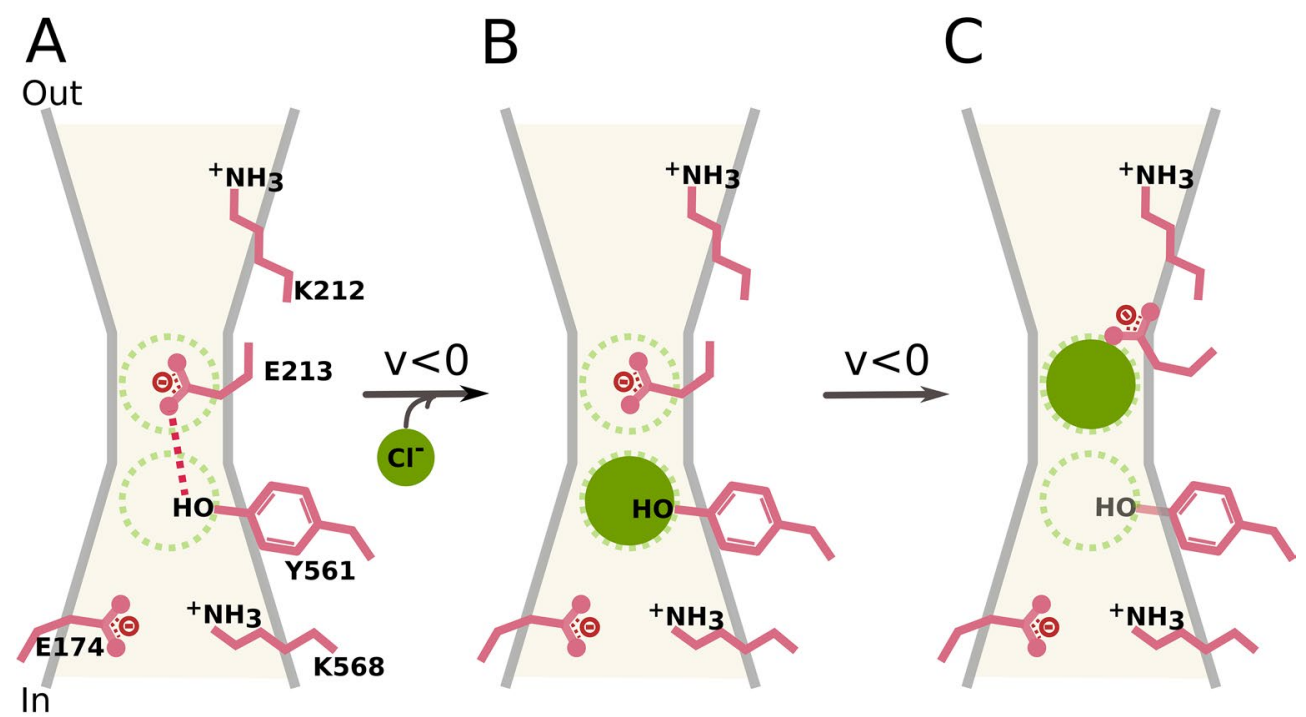

Figure 7. Schematic representation of the electro-steric activation of CLC-2. The Scheme depicts one pore and the side chains of E174, K568, Y561, E213 and K212 lining the pore. The empty pore remains closed by the Y561-E213 gate (A). Upon a hyperpolarization $(\mathrm{V}<0)$, intracellular $\mathrm{Cl}^{-}$occupies the pore initiating the activation process (B). The gate is splited by electro-steric repulsion and E213 adopts an outward-facing conformation thus coupling permeation to gating (C).

coupled. However, despite that $\mathrm{E}$ and $\mathrm{Y}$ seems to be coupled by a hydrogen bond in CLC-0 and CLC-1, only common gating is altered by mutating the central $\mathrm{Y}^{33}$. The reason for this discrepancy with our results is unknown but it may reflect the intrinsic differences in voltage-dependent gating in CLC-0, CLC-1, and CLC-2 channels.

Our results showed that permeant anions induce local conformational changes that are fundamental steps for gate-opening. In the closed state, E213 and Y561 are coupled (Fig. 7A). During the permeation process, the pore is occupied by more than one permeant anion. Permeating $\mathrm{Cl}^{-}$ions encounter the $\mathrm{Y} 561-\mathrm{E} 213$ gate and split it by electro-steric repulsion (Fig. 7B). In the WT channel, permeant $\mathrm{Cl}^{-}$repels E213 outwardly forcing E213 to adopt an outward-facing conformation (Fig. 7C). The separation of these residues by $\mathrm{Cl}^{-}$effectively coupled anion permeation to pore gating to then enable anion permeation. We think that the Y561-E213 gate operates as a one-way check valve as has been proposed for K2P potassium channels ${ }^{8}$. E213 moves outwardly whereas Y561 prevents E213 from opening in the inward direction and shielding E213 from intracellular $\mathrm{H}^{+}$.

The structures of $\mathrm{CLC} \mathrm{Cl} / \mathrm{H}^{+}$exchangers and hCLC-1 show a pore that splits into two pathways at the cytosolic end. The canonical pathway transports $\mathrm{Cl}^{-}$whereas the alternative pathway serves as an entryway for $\mathrm{H}^{+}$to reach the glutamate gate ${ }^{39}$. The homology structure of CLC-2 shows an alternative pathway disconnected from the canonical pore. Thus, if the alternative water pathway serves as the $\mathrm{H}^{+}$pathway but remains unplugged from the main pore, then E213 would not be protonated as we showed ${ }^{40}$.

A recent molecular dynamics simulation study of a CLC-2 homology structure reported that CLC-2 pore gating could indeed be $\mathrm{Cl}^{-}$dependent ${ }^{32}$. The authors used Markov state modelling and MD simulation of a homology structure of rat CLC-2. They proposed that entry of intracellular $\mathrm{Cl}^{-}$requires rotation of the S168GI170 backbones and opening of E213 follows this step in a $\mathrm{Cl}^{-}$dependent manner. However, they suggest that Y561 (Y559 in their homology structure) is irrelevant for CLC-2 gating. We agree with the $\mathrm{Cl}^{-}$dependence of CLC-2 gating, however, we have found that Y561 residue is critical for CLC-2 gating. Our mutational analysis demonstrated that Y561 holds E213 in the closed position and hinders E213 protonation. One possible explanation for this discrepancy would be the use of only one subunit to perform MD simulations. Experimental results suggest that the fast and slow gates are coupled in CLC- $2^{27,41}$. Thus, residues forming the pore or residues participating in gating could have different conformational states in a homodimer than in a monomer. Also, the MD data were collected at $0 \mathrm{mV}$. At this voltage, the open probability of the gate is almost zero, which decreases the likelihood of observing conformational changes associated with gating.

We consider that an electro-steric gating mechanism might occur in other channels. For example, the voltage sensor-less $\mathrm{K} 2 \mathrm{P} \mathrm{K}^{+}$channels display voltage dependence due to $\mathrm{K}^{+}$ions movement along the pore ${ }^{8,42}$. Similarly, the voltage-dependent gating of viral $\mathrm{K}^{+}$channel $\mathrm{Kcv}_{\mathrm{NTS}}$ could rely on occupation by $\mathrm{K}^{+}$of an external site ${ }^{43}$. Also, the outward movement of ions could explain the activation of PIEZO channels by voltage alone ${ }^{44}$. CLC- 0 and CLC-1 show AMF behaviour, permeant anions facilitate gating, and non-permeant anions support voltagedependent gating in CLC-1 ${ }^{18,19,22,24,25,45}$ and the glutamate gate-less CLC-K is endowed with voltage-dependent gating after introducing a pore glutamate ${ }^{46}$. Thus, coupling ion permeation to pore gating in ionic channels might be more common than previously anticipated. Additional experiments combining functional, mutagenesis and structural analysis are needed to fully understand the gating coupled to the permeation. 


\section{Methods}

Homology models of mouse CLC-2 and preparation of membrane-protein ensembles. We constructed the CLC-2 $2^{\mathrm{CLC}-\mathrm{K}}$ model for the structure of the CLC-2 $\mathrm{Cl}^{-}$channel (908 aa) using the I-Tasser ${ }^{47}$ server (https://zhanglab.ccmb.med.umich.edu/I-TASSER/) and the bovine CLC-K structure (5TQQ; Uniprot: E1B792; $687 \mathrm{aa})$ solved at $3.76 \AA$ using cryo-EM ${ }^{14}$. Additional models, termed CLC-2 ${ }^{\mathrm{CLC}-1}$, were built using as templates the hCLC-1 structures determined by cryo-EM (6COY, 6QV6, 6QVB, 6QVU; UniProt: P35523; 988 aa) ${ }^{13}$, later available. hCLC-1 structures are truncated versions (469-626 residues by monomer) solved at $3.36 \AA$ (6COY), $4.34 \AA$ (6QVB), $3.63 \AA$ (6QV6), and $4.20 \AA$ (6QVU).

The protonation state of ionisable residues at $\mathrm{pH} 7.3$ was determined by PROPKA ${ }^{48}$. The structures were embedded in symmetric bilayers of 1,2-dimyristoyl-sn-glycerol-3-phosphocholine (DMPC) or 1-palmitoyl2-oleoyl-sn-glycero-3-phosphocholine (POPC) generated using CHARMM-GUI ${ }^{49}$ membrane builder (http:// www.charmm-gui.org) and oriented using the Positioning of Proteins in Membrane server (PPM, http://opm. phar.umich.edu/server.php). The structures were solvated with water modelled by TIP3 ${ }^{50}$ and $140 \mathrm{mM} \mathrm{NaCl}$. The ensembles containing CLC-2 $2^{\mathrm{CLC}-\mathrm{K}}$ and CLC-2 $2^{\mathrm{CLC}-1}$ consisted of $785 \mathrm{DMPC}, 102741 \mathrm{TIP} 3,800 \mathrm{Na}^{+}$and 416 $\mathrm{Cl}^{-}$contained in a $170 \times 170 \times 158 \AA^{3}$ simulation box, and 554 POPC, $43283 \mathrm{TIP} 3,110 \mathrm{Na}^{+}$, and $130 \mathrm{Cl}^{-}$contained in a $176 \times 171 \times 100 \AA^{3}$ box, respectively.

Cell culture, transient expression, and electrophysiological recordings. The study was carried out in compliance with the ARRIVE guidelines (https://arriveguidelines.org/). Wild type and mutant mouse CLC-2 channels were expressed in HEK-293 and X. oocytes and the macroscopic currents were recorded using the patch clamp and cut-open oocyte voltage clamp, respectively, as previously described ${ }^{15-17,27,51,52}$. WT or mutant DNAs were inserted in pIRES-II (for HEK-293 expression) o pGEM-T vectors (for X. laevis expression). HEK-293 cells were transiently transfected with $0.5 \mu \mathrm{g} / \mu \mathrm{l}$ of DNA using lipofectamine (Qiagen Inc., Valencia, CA, USA) following the manufacturer's instructions. Mature X. laevis frogs, purchased from Aquanimals SA de $\mathrm{CV}$, Querétaro, Mexico, were used to isolate oocytes via survival surgery. Frogs were care in accordance with Norma Oficial Mexicana NOM-062-ZOO-1999 and with guidelines of the Institutional Committee for Care and Use of Laboratory Animals from University Centre for Exact and Engineering Sciences of the University of Guadalajara (Comité Institucional del Cuidado y Uso de Animales en el Laboratorio CICUAL-CUCEI-UDG). The Institutional Committee for Care and Use of Laboratory Animals from University Centre for Exact and Engineering Sciences of the University of Guadalajara approved the frog oocytes isolation method and the cut oocytes electrophysiology experiments. Frogs were anesthetized with $0.1 \%$ tricaine (3-aminobenzoic acid ethyl ester) and a small portion of the ovary lobes containing oocytes was extracted. Oocytes were isolated under mechanical agitation and with the treatment of collagenase type II (Worthington Biochemical Corp., NJ, USA). Each oocyte was injected with $40 \mathrm{ng}$ of RNA in-vitro transcribed using the T7 promoter mMESSAGE cRNA kit (Ambion, Austin, TX., USA) and DNA linearized with PmeI enzyme (New England Biolabs, Inc., Ipswich, MA, USA). Oocytes were incubated for $2-7$ days at $17^{\circ} \mathrm{C}$ in a standard oocyte saline solution. For patch-clamp, external and internal solutions contained (in mM): TEA-Cl 139, $\mathrm{CaCl}_{2}$ 0.5, HEPES 20 and D-mannitol 100; and, TEA-Cl 140, HEPES 20 and EGTA 20, respectively, and the $\mathrm{pH}$ was adjusted to 7.3 with TEA-OH. HEPES was substituted by MES to prepare solutions with low $\mathrm{pH}$. The average tonicity of external and internal solutions was $387.9 \pm 1.9$ and $347.3 \pm 2.6 \mathrm{mOsm} / \mathrm{kg}$, respectively. For whole cell recordings, cells were held at $0 \mathrm{mV}$, followed by voltages steps to vary the membrane potential between +60 or +200 to $-160 \mathrm{mV}$ in $20 \mathrm{mV}$ increments and then repolarizing to +60 or $+80 \mathrm{mV}$. Currents were recorded using pCLAMP 8 or 10 and a sampling rate of $500 \mathrm{kHz}$. For cut open oocyte recordings, the external and internal solutions contained (in mM): $130 \mathrm{NMDG}-\mathrm{HCl}, 4$ $\mathrm{MgCl}_{2}, 1 \mathrm{BaCl}_{2}$ and $10 \mathrm{HEPES}$; and $136 \mathrm{NMDG}$ (N-methyl-D-glucamine)-HCl, $2 \mathrm{MgCl}_{2}, 10 \mathrm{EGTA}, 10 \mathrm{HEPES}$, respectively, and the $\mathrm{pH}$ was adjusted to 7.3 with $\mathrm{NMDG}$. Internal solutions with different $\mathrm{SCN}^{-}$or acetate mole fractions were prepared by mixing solutions containing $100 \% \mathrm{Cl}^{-}$with $100 \% \mathrm{SCN}^{-}$or acetate. Currents were filtered at $10 \mathrm{kHz}$ and digitized at $100 \mathrm{kHz}$. All experiments were performed at room temperature $\left(21-23^{\circ} \mathrm{C}\right)$. Mutations were performed using standard PCR techniques and confirmed by sequencing. All chemicals were purchased from Sigma-Aldrich (St. Louis, MO, USA).

Analysis. Current recordings were analysed with Clampfit or Analysis (UCLA, Los Angeles, CA, USA). Membrane and reversal potentials $\left(\mathrm{V}, \mathrm{E}_{\mathrm{r}}\right)$ were corrected off-line using measured liquid junction potentials ${ }^{53}$. Recordings were analysed if $\mathrm{E}_{\mathrm{r}}$ was near $\mathrm{Cl}^{-}$Nernst potential. $\mathrm{W}_{\mathrm{P}}$ and $\mathrm{W}_{\mathrm{C}}$ (fractional contribution of the fast and slow components) and $\tau_{\mathrm{f}}$ and $\tau_{\mathrm{s}}$ (fast and slow time constants) were calculated by fitting the whole cell currents with a double exponential function:

$$
I_{C l}=A_{1}\left(1-\exp ^{\frac{-t}{\tau_{f}}}\right)+A_{2}\left(1-\exp ^{\frac{-t}{\tau_{s}}}\right)+A_{0}
$$

where $W_{P}=A_{1} /\left(A_{0}+A_{1}+A_{2}\right), W_{C}=A_{2} /\left(A_{0}+A_{1}+A_{2}\right)$, and $W_{\text {cons }}=A_{0} /\left(A_{0}+A_{1}+A_{2}\right)$. $\mathrm{E}_{\mathrm{r}}$ was determined from instantaneous $\mathrm{I}_{\mathrm{Cl}}-\mathrm{V}$ plots. Conductance $(\mathrm{G})$ at each $\mathrm{V}$ was calculated as $\mathrm{I}_{\mathrm{Cl}} /\left(\mathrm{V}-\mathrm{E}_{\mathrm{r}}\right)$. The open probabilities of the pore $\left(\mathrm{P}_{\mathrm{p}}\right)$ and common $\left(\mathrm{P}_{\mathrm{C}}\right)$ gates were calculated as described before ${ }^{27}$. Briefly, the time constant of the pore gate is $\leq 8 \mathrm{~ms}$, thus, a $15 \mathrm{~ms}$ hyperpolarization to $-200 \mathrm{mV}$ drives it into the fully open state $\left(P_{p} \sim 1\right)$. Thus, we intercalated a $15 \mathrm{~ms} /-200 \mathrm{mV}$ pulse in test $\mathrm{V}$ after the current reached its steady state. The ratio of the steady-state current $\left(=i^{*} N_{T}{ }^{*} P p^{*} P c\right.$ where $P_{p}{ }^{*} P_{C}=P_{A}, i$ is the single-channel current and $N_{T}$ is the total number of channels) to the current immediately after the $15 /-200 \mathrm{mV}$ pulse $\left(=i^{\star} N_{T}{ }^{*} P c\right)$, both sampled at the same $\mathrm{V}$, is equal to $\mathrm{P}_{\mathrm{p}}$. This protocol was applied at different $\mathrm{V}$ test to obtain $P_{p}$ as a function of $\mathrm{V}$. $P_{C}$ was calculated as $P_{A} / P_{P}$ with $\mathrm{P}_{\mathrm{A}}\left(=G / G_{\text {max }}\right)$ determined in the same cell. The maximum conductance $\left(\mathrm{G}_{\max }\right)$ was estimated before 
normalization by fitting $\mathrm{G}-\mathrm{V}$ curves with a single term Boltzmann equation. We determined the $\mathrm{V}$ dependence from fits of $\mathrm{P}_{\mathrm{A}}-\mathrm{V}, \mathrm{P}_{\mathrm{P}}-\mathrm{V}$ or $\mathrm{P}_{\mathrm{C}}-\mathrm{V}$ curves with a single or two terms Boltzmann equation (Eq. 3):

$$
\frac{1}{1+\exp ^{-\frac{z_{O} F}{R T}\left(V-V_{0.5, O}\right)}}+\frac{1}{1+\exp ^{-\frac{z_{r O} F}{R T}\left(V-V_{0.5, r O}\right)}}
$$

where $\mathrm{z}_{\mathrm{O}}$ and $\mathrm{z}_{\mathrm{rO}}$ are the apparent charge of the opening at negative $\mathrm{V}$ and re-opening at positive $\mathrm{V}$, respectively, $\mathrm{F}$ is the Faraday constant, $\mathrm{R}$ is the gas constant, $\mathrm{T}$ is the temperature, and $\mathrm{V}_{0.5, \mathrm{O}}$ and $\mathrm{V}_{0.5, \mathrm{rO}}$ are the $\mathrm{V}$ needed to reach half value of its sigmoid effects. Data are plotted as mean \pm SEM of $n$ (number of independent experiments). Figures and fits were done using Origin (Origin Lab, Northampton, MA). Dashed black lines in Figures indicate $\mathrm{I}_{\mathrm{Cl}}=0$.

Non-stationary noise analysis was performed as we described previously ${ }^{54}$. Shortly, WT ClC-2 and Y561A mutant currents were recorded at 100 and $-100 \mathrm{mV}$ repetitively (50-100 times) during $200 \mathrm{~ms}$. The time-dependent variance $\left(\sigma^{2}\right)^{55}$ :

$$
\sigma^{2}(t)=\frac{1}{2(M-1)} \sum_{j=1}^{M-1}\left[I_{j+1}(t)-I_{j}(t)\right]^{2}
$$

where $M$ is the total number of traces and $I_{j+1}$ and $I_{j}$ are two consecutive currents. The total number of channels $(N)$ and single current (i) were determined by fitting the $\sigma^{2}$ vs mean current $(\bar{I})$ relationship with the equation ${ }^{38}$ :

$$
\sigma^{2}=\left(1+P_{P}\right) \bullet i \bullet \bar{I}-\frac{\bar{I}^{2}}{N}
$$

$P_{P}$ is the open probability of the pore. For WT CLC-2 $P_{P}=0$ at $+100 \mathrm{mV}$, and $P_{P}=1$ in Y561A mutant at $-100 \mathrm{mV}$.

A one-way ANOVA with a Tukey post hoc test $(\mathrm{p}<0.01)$ was used to test the statistical differences between the mean values of the voltage-dependent parameters. Significant differences are indicated by an asterisk, crosses or double dagger.

Received: 26 October 2020; Accepted: 4 June 2021

Published online: 23 June 2021

\section{References}

1. Hille, B., Armstrong, C. M. \& MacKinnon, R. Ion channels: From idea to reality. Nat. Med. 5, 1105-1109. https://doi.org/10.1038/ 13415 (1999).

2. Bezanilla, F. How membrane proteins sense voltage. Nat. Rev. Mol. Cell Biol. 9, 323-332 (2008).

3. Long, S. B., Campbell, E. B. \& MacKinnon, R. Voltage sensor of Kv1.2: Structural basis of electromechanical coupling.Science 309, 903-908. https://doi.org/10.1126/science.1116270 (2005).

4. Jiang, Y., Ruta, V., Chen, J., Lee, A. \& Mackinnon, R. The principle of gating charge movement in a voltage-dependent K+ channel. 423, 42-48 (2003).

5. Bezanilla, F. Voltage sensor movements. J. Gen. Physiol. https://doi.org/10.1085/jgp.20028660 (2002).

6. Cox, C. D., Bavi, N. \& Martinac, B. Origin of the force: The force-from-lipids principle applied to piezo channels. Curr. Top. Membr. https://doi.org/10.1016/bs.ctm.2016.09.001 (2016).

7. Goldschen-Ohm, M. P. \& Chanda, B. SnapShot: Channel gating mechanisms. Cell 170, 594-594.e1 (2017).

8. Schewe, M. et al. A non-canonical voltage-sensing mechanism controls gating in K2P K+ channels. Cell 164, 937-949 (2016).

9. Hilgemann, D. W. Regulation of ion transport from within ion transit pathways. J. Gen. Physiol. 152, 1-13 (2020).

10. Jentsch, T. J. \& Pusch, M. CLC chloride channels and transporters: Structure, function, physiology, and disease. Physiol. Rev. https:// doi.org/10.1152/physrev.00047.2017 (2018).

11. Dutzler, R., Campbell, E. B., Cadene, M., Chait, B. T. \& MacKinnon, R. X-ray structure of a ClC chloride channel at 3.0 A reveals the molecular basis of anion selectivity. Nature 415, 287-294. https://doi.org/10.1038/415287a (2002).

12. Dutzler, R., Campbell, E. B. \& MacKinnon, R. Gating the selectivity filter in ClC chloride channels. Science 300, 108-112 (2003).

13. Park, E. \& MacKinnon, R. Structure of the CLC-1 chloride channel from Homo sapiens. Elife 7. https://doi.org/10.7554/eLife. 36629.001 (2018).

14. Park, E., Campbell, E. B. \& MacKinnon, R. Structure of a CLC chloride ion channel by cryo-electron microscopy. Nature 541, 500-505 (2017).

15. Sánchez-Rodríguez, J. E., De Santiago-Castillo, J. A. \& Arreola, J. Permeant anions contribute to voltage dependence of ClC-2 chloride channel by interacting with the protopore gate. J. Physiol. 588, 2545-2556 (2010).

16. Sánchez-Rodríguez, J. E. et al. Sequential interaction of chloride and proton ions with the fast gate steer the voltage-dependent gating in ClC-2 chloride channels. J. Physiol. 590, 4239-4253 (2012).

17. De Jesús-Pérez, J. J. et al. Gating the glutamate gate of CLC-2 chloride channel by pore occupancy. J. Gen. Physiol. 147, 25-37 (2016).

18. Pusch, M., Ludewig, U., Rehfeldt, A. \& Jentsch, T. J. Gating of the voltage-dependent chloride channel CIC-0 by the permeant anion. Nature https://doi.org/10.1038/373527a0 (1995).

19. Chen, T.-Y. Coupling gating with ion permeation in ClC channels. Sci. STKE 188, pe23. https://doi.org/10.1126/stke.2003.188. pe23 (2003).

20. Niemeyer, M. I., Cid, L. P., Yusef, Y. R., Briones, R. \& Sepúlveda, F. V. Voltage-dependent and -independent titration of specific residues accounts for complex gating of a ClC chloride channel by extracellular protons. J. Physiol. 587, 1387-1400 (2009).

21. Traverso, S., Zifarelli, G., Aiello, R. \& Pusch, M. Proton sensing of CLC-0 mutant E166D. J. Gen. Physiol. 127, 51-65 (2006).

22. Chen, T. Y. \& Miller, C. Nonequilibrium gating and voltage dependence of the ClC-0 Cl- channel. J. Gen. Physiol. 108, 237-250 (1996).

23. Rychkov, G. Y., Pusch, M., Astill, D. S., Roberts, M. L., Jentsch, T. J. \& Bretag, A. H. Concentration and pH dependence of skeletal muscle chloride channel ClC-1. J. Physiol. 497, 423-435 (1996). 
24. Rychkov, G. Y., Pusch, M., Roberts, M. L., Jentsch, T. J. \& Bretag, A. H. Permeation and block of the skeletal muscle chloride channel, ClC-1, by foreign anions. J. Gen. Physiol. 111, 653-665 (1998).

25. Jentsch, T. J. \& Pusch, M. CLC chloride channels and transporters: Structure, function, physiology, and disease. Physiol. Rev. 98, $1493-1590$ (2018).

26. Miller, C. ClC chloride channels viewed through a transporter lens. Nature 440, 484-489 (2006).

27. De Santiago, J. A., Nehrke, K. \& Arreola, J. Quantitative analysis of the voltage-dependent gating of mouse parotid ClC-2 chloride channel. J. Gen. Physiol. 126, 591-603 (2005).

28. Thiemann, A., Gründer, S., Pusch, M. \& Jentsch, T. J. A chloride channel widely expressed in epithelial and non-epithelial cells. Nature https://doi.org/10.1038/356057a0 (1992).

29. Niemeyer, M. I., Cid, L. P., Yusef, Y. R., Briones, R. \& Sepúlveda, F. V. Voltage-dependent and -independent titration of specific residues accounts for complex gating of a $\mathrm{ClC}$ chloride channel by extracellular protons. J. Physiol. https://doi.org/10.1113/jphys iol.2008.167353 (2009).

30. Boccaccio, A. \& Pusch, M. TMEM16 Ca2+ activated Cl- channels and CLC chloride channels and transporters. in The Oxford Handbook of Neuronal Ion Channels. https://doi.org/10.1093/oxfordhb/9780190669164.013.17 (Oxford University Press, 2018).

31. Wang, K. et al. Structure of the human ClC-1 chloride channel. PLoS Biol. 17, 1-20 (2019).

32. McKiernan, K. A., Koster, A. K., Maduke, M. \& Pande, V. S. Dynamical model of the CLC-2 ion channel reveals conformational changes associated with selectivity-filter gating. PLoS Comput. Biol. https://doi.org/10.1371/journal.pcbi.1007530 (2020).

33. Bennetts, B. \& Parker, M. W. Molecular determinants of common gating of a ClC chloride channel. Nat. Commun. 4, 2507 (2013).

34. Arreola, J., Begenisich, T. \& Melvin, J. E. Conformation-dependent regulation of inward rectifier chloride channel gating by extracellular protons. J. Physiol. 541, 103-112 (2002).

35. Carter, P. J., Winter, G., Wilkinson, A. J. \& Fersht, A. R. The use of double mutants to detect structural changes in the active site of the tyrosyl-tRNA synthetase (Bacillus stearothermophilus). Cell 38, 835-840 (1984).

36. Horovitz, A. Double-mutant cycles: A powerful tool for analyzing protein structure and function. Fold. Des. 1, R121-R126 (1996).

37. Yifrach, O. \& Mackinnon, R. Energetics of pore opening in a voltage-gated $\mathrm{K}$ channel . Cell 111, 231-239 (2002).

38. Stölting, G. et al. Regulation of ClC-2 gating by intracellular ATP. Pflugers Arch. Eur. J. Physiol. 465, 1423-1437 (2013).

39. Accardi, A. et al. Separate ion pathways in a Cl- /H+ exchanger. J. Gen. Physiol. 126, 563-570 (2005).

40. De Jesús-Pérez, J. J., Méndez-Maldonado, G. A., Gonzalez-Hernandez, I. L., De la Rosa, V., Gastélum-Garibaldi, R., SánchezRodríguez, J. E. \& Arreola, J. Electro-steric mechanism of CLC-2 chloride channel activation. bioRxiv. https://doi.org/10.1101/ 2020.06.12.148783(2020).

41. Yusef, Y. R. et al. Removal of gating in voltage-dependent ClC-2 chloride channel by point mutations affecting the pore and C-terminus CBS-2 domain. J. Physiol. 572, 173-181 (2006).

42. Kopec, W., Rothberg, B. S. \& de Groot, B. L. Molecular mechanism of a potassium channel gating through activation gate-selectivity filter coupling. Nat. Commun. 10, 5366. https://doi.org/10.1038/s41467-019-13227-w (2019).

43. Rauh, O., Hansen, U. P., Scheub, D. D., Thiel, G. \& Schroeder, I. Site-specific ion occupation in the selectivity filter causes voltagedependent gating in a viral K+ channel. Sci. Rep. 8, 1-15 (2018).

44. Moroni, M., Servin-Vences, M. R., Fleischer, R., Sánchez-Carranza, O. \& Lewin, G. R. Voltage gating of mechanosensitive PIEZO channels. Nat. Commun. 9, 1096. https://doi.org/10.1038/s41467-018-03502-7 (2018).

45. Rychkov, G. Y., Pusch, M., Roberts, M. L. \& Bretag, A. H. Interaction of hydrophobic anions with the rat skeletal muscle chloride channel ClC-1: Effects on permeation and gating. J. Physiol. 530, 379-393 (2001).

46. Waldegger, S. \& Jentsch, T. J. Functional and structural analysis of ClC-K chloride channels involved in renal disease. J. Biol. Chem. 275, 24527-24533 (2000).

47. Roy, A., Kucukural, A. \& Zhang, Y. I-TASSER: A unified platform for automated protein structure and function prediction. Nat. Protoc. 5, 725-738 (2010).

48. Olsson, M. H. M., SØndergaard, C. R., Rostkowski, M. \& Jensen, J. H. PROPKA3: Consistent treatment of internal and surface residues in empirical p K a predictions. J. Chem. Theory Comput. 7, 525-537. https://doi.org/10.1021/ct100578z (2011).

49. Jo, S., Kim, T., Iyer, V. G. \& Im, W. CHARMM-GUI: A web-based graphical user interface for CHARMM. J. Comput. Chem. https:// doi.org/10.1002/jcc.20945 (2008).

50. Jorgensen, W. L., Chandrasekhar, J., Madura, J. D., Impey, R. W. \& Klein, M. L. Comparison of simple potential functions for simulating liquid water. J. Chem. Phys. 79, 926-935 (1983).

51. Stefani, E. \& Bezanilla, F. Cut-open oocyte voltage-clamp technique. Methods Enzymol. 293, 300-318 (1998).

52. Rodríguez-Rangel, S., Bravin, A. D., Ramos-Torres, K. M., Brugarolas, P. \& Sánchez-Rodríguez, J. E. Structure-activity relationship studies of four novel 4-aminopyridine K+ channel blockers. Sci. Rep. https://doi.org/10.1038/s41598-019-56245-w (2020).

53. Neher, E. Correction for liquid junction potentials in patch clamp experiments. Methods Enzymol. https://doi.org/10.1016/00766879(92)07008-C (1992).

54. Cruz-Rangel, S. et al. Extracellular protons enable activation of the calcium-dependent chloride channel TMEM16A. J. Physiol. 595, 1515-1531 (2017).

55. Sigworth, F. The variance of sodium current fluctuations at the node of Ranvier. J. Physiol. 307, 97-129 (1980).

\section{Acknowledgements}

The authors thank Dr Patricia Perez-Cornejo for critical comments, CY Hernandez-Carballo for technical assistance. The work was supported by grant FORDECYT-PRONACES 13080522019 from CONACyT, Mexico, and by FAI-UASLP C20-FAI-10-06.06 200040006, Mexico. RG-G is a recipient of Graduate Student Fellowship \#726278 from CONACyT, Mexico. JJDeJ-P was supported by a Graduate Student Fellowship and Postdoctoral Fellowship \#234820 and \#711128 from CONACyT, Mexico, respectively.

\section{Author contributions}

D.J.-P.: Designed research, performed patch-clamp experiments, performed MD simulations, analysed data, and wrote the manuscript. M.-M.: Performed homology modelling, analysed the data, and wrote the manuscript. L.-R.: Performed patch-clamp experiments. E.-J.: Performed anomalous mole fraction experiments. G.-H.: Performed patch-clamp experiments. D.l.R.: Performed patch-clamp experiments, analysed data, and review the manuscript. G.-G. and S.-R.: Performed electrophysiological experiments in X. oocytes, analysed the data, and wrote the manuscript. J.A.: Planned research, analysed data, wrote the paper, and secured funds.

\section{Competing interests}

The authors declare no competing interests. 


\section{Additional information}

Supplementary Information The online version contains supplementary material available at https://doi.org/ 10.1038/s41598-021-92247-3.

Correspondence and requests for materials should be addressed to J.A.

Reprints and permissions information is available at www.nature.com/reprints.

Publisher's note Springer Nature remains neutral with regard to jurisdictional claims in published maps and institutional affiliations.

(c) (1) Open Access This article is licensed under a Creative Commons Attribution 4.0 International cc) License, which permits use, sharing, adaptation, distribution and reproduction in any medium or format, as long as you give appropriate credit to the original author(s) and the source, provide a link to the Creative Commons licence, and indicate if changes were made. The images or other third party material in this article are included in the article's Creative Commons licence, unless indicated otherwise in a credit line to the material. If material is not included in the article's Creative Commons licence and your intended use is not permitted by statutory regulation or exceeds the permitted use, you will need to obtain permission directly from the copyright holder. To view a copy of this licence, visit http://creativecommons.org/licenses/by/4.0/.

(C) The Author(s) 2021 